\title{
Are There Price Asymmetries in the U.S. Beef Market?
}

\begin{abstract}
We examine price transmissions among farm, wholesale and retail U.S. beef markets using two types of retail price data, one collected by the Bureau of Labor Statistics (BLS), and the other one collected at the point of sale using electronic scanners. Using a test based on the simulation of nonlinear impulse response functions, we find no evidence of vertical asymmetric price transmissions in models estimated using scanner data. However, prices adjust asymmetrically in models estimated using BLS data. Because scanner prices are more reflective of actual consumer purchases, the U.S. beef market is not as inefficient as previous studies suggest.
\end{abstract}

Keywords: Price asymmetry, BLS prices, scanner prices, nonlinear impulse response functions, beef market, threshold vector error correction models.

JEL Classifications: Q13, Q18, C32, C53. 


\section{Are There Price Asymmetries in the U.S. Beef}

\section{Market?}

\section{Introduction}

Farm, wholesale and retail meat price relationships have been ardently debated for a long time in the U.S. Since the 1970s, numerous congressional hearings and commissions have addressed price transmissions among vertically linked meat markets (Koontz and Ward, 2011). ${ }^{1}$ The focus of this debate has been on economic and agricultural policy issues related to market concentration, welfare distribution, and market efficiency. An often noted concern raised by both producers and consumers is the growing gap between farm and retail meat prices. Claims persist that producers do not benefit from downstream price increases, in the same magnitude or speed, as downstream price decreases. For instance, a decrease in retail beef price due to a decrease in beef demand passes to farm prices faster than a retail price increase (U.S. Department of Justice, 2012). ${ }^{2}$ From a consumer perspective, there are concerns that retail and wholesale meat prices are rigid or slow to respond to farm price declines, but responsive to farm price increases. Consequently, cost increases are transferred on to consumers more rapidly than costs savings (Abdulai, 2002).

Economic theory provides several mechanisms by which there could be asymmetric

\footnotetext{
${ }^{1}$ The interest of policymakers can at least partially be explained by the size of the U.S. beef industry, which had a retail equivalent value of $\$ 105$ billion as of 2015 (U.S. Department of Agriculture (USDA), Economic Research Service, 2016).

${ }^{2}$ Beef cattle producers attribute the increase in farm-to-retail price spreads, and consequently the decline in the farmer's share of the dollar consumers spend on food, as evidence of a lack of competitiveness among middlemen along the beef supply chain. This claim is based on the high levels of market concentration among meat packing firms and large retailers, which enables them to potentially exercise market power (Crespi, Saitone and Sexton, 2012). As documented by the USDA, the national four-firm concentration ratio for steer and heifer slaughter increased from 25\% in 1976 to 85\% in 2015 (USDA Grain Inspection, Packers and Stockyards Administration, 2016).
} 
price responses in vertically linked markets including market power and concentration at processing and retail levels (e.g., Azzam, 1999; Bailey and Brorsen, 1989; Peltzman, 2000; Xia, 2009); menu costs (e.g., Bailey and Brorsen, 1989; Levy, 1997); inventory adjustment practices (e.g., Blinder, 1982); government intervention (e.g., Kinnucan and Forker, 1987; Mohanty, Peterson and Kruse, 1995); consumption inertia (Xia and Li, 2010); and empirical methodology employed in testing for asymmetry (Miller and Hayenga, 2001). However, a necessary condition for accurately assessing price asymmetry in these markets is that the data used for analyses are adequate (Bailey and Brorsen, 1989; von Cramon-Taubadel, 1998). For retail meat prices especially, concerns exist regarding the accuracy of traditional data series (Lensing and Purcell, 2006).

Retail prices collected by the Bureau of Labor Statistics (BLS) are used widely in a large body of published research. However, evidence suggests that these data are biased and do not fully capture retail price variability over time (Hausman, 2003). That is, BLS price data do not accurately reflect volume-weighted sales of beef products. Instead, BLS price data simply reflect posted shelf prices on beef products with limited adjustment for actual volume of beef that is sold at each price level, particularly at discounted prices during retail specials (Lensing and Purcell, 2006). Thus causing a significant upward bias on price estimates. This issue raises the question of whether findings from previous studies that have used BLS retail price data are reliable.

The Livestock Mandatory Reporting Act of 1999 mandated collection of farm and wholesale meat prices to facilitate open, transparent price discovery and provide market participants with comparable levels of market information for cattle, swine, sheep, beef, and lamb meat. The Act also required the U.S. Department of Agriculture (USDA) to investigate the use of an alternative source of retail meat prices that would provide retail price data more reflective of actual consumer purchases than BLS data. The purpose of this provision was to address concerns regarding the quality of BLS retail meat price data (Hahn, Perry and Southard, 2009). As an alternative to BLS retail meat price data, scanner based 
quantity-weighted retail price data was considered. Scanner data are collected at the point of sale by supermarkets using electronic scanners in check-out lines. Unlike BLS price data, scanner data enables accounting for volume of sales and discounted prices in summarizing prices each period.

In addition to the concerns regarding the quality of data used in studies assessing asymmetric price transmissions, other substantial issues are the empirical methodology employed to test for asymmetry and the frequency of the data employed. Meyer and von Cramon-Taubadel (2004) indicate that different methods lead to different rates of rejection of the null hypothesis of symmetry and conclude that asymmetry findings in existing literature have been method-driven. Furthermore, von Cramon-Taubadel (1998) argues that data frequency influences asymmetry test results. In particular, if price transmission between two markets is asymmetric in the short-run but symmetric in the long-run, estimation with low frequency data will reflect the latter and fail to expose the former. Therefore, another important question is whether asymmetric price transmission findings are sensitive to both testing methods and data frequency employed.

The objective of this study is to determine the sensitivity of price asymmetry results to specific retail price series, testing methods employed, and data frequency. More specifically, we compare price transmissions using two distinct types of retail beef prices that differ according to their collection procedure: BLS retail price data and scanner quantity-weighted retail price data. To test for and quantify asymmetric responses we adopt a new method that is based on the simulation of nonlinear impulse response functions. This method is then contrasted with more traditional approaches such as those used by Goodwin and Holt (1999). ${ }^{3}$ To test whether price asymmetry results differ when using data of different frequencies we estimate our models using both monthly and weekly data.

The methods used in this study involve the estimation of nonlinear structural vector

\footnotetext{
${ }^{3}$ Consistent with other work, Goodwin and Holt (1999) found statistically significant thresholds and asymmetries in price adjustments in the U.S. beef market chain.
} 
autoregressive (SVAR) models that allow for asymmetric responses of retail, wholesale, and farm prices to shocks to any of these series. Impulse response functions are then computed by simulation following the extension of Koop, Pesaran and Potter (1996) proposed by Kilian and Vigfusson (2011). We use this information to calculate the degree of asymmetry following shocks to each of the price series. ${ }^{4}$ Finally, we conduct a counterfactual analysis to check whether our results are due to an uninformative dataset that causes the test for asymmetric responses to have low power.

In this study, we find evidence indicating that price asymmetry results are sensitive to the choice of retail beef price series. We do not reject the null hypothesis of symmetric responses to shocks at any point in the distribution chain when models are estimated using scanner retail price data. On the other hand, when the scanner data is replaced with the widely-used BLS retail price series, we do find evidence of asymmetric price responses in some cases. What can account for the difference in results when changing the retail beef price series? The USDA began collecting scanner data in response to concerns about the quality of BLS retail meat price data (Hahn, Perry and Southard, 2009). The quantity-weighted retail scanner price data should better reflect the price that consumers actually pay for beef, and our results do support that notion, as we find that scanner retail prices are much more responsive than BLS prices to upstream price changes. We also find that asymmetry results are robust to the use of different methods and data frequency.

Our results have important implications for the U.S. beef market. First, since price is the primary link between vertically integrated markets, the analysis of price transmissions is fundamental to understand how markets operate (e.g., marketing margins, spreads and pricing practices). Second, this analysis has implications for policy makers because the presence of asymmetry implies a different distribution of welfare than under symmetry. Therefore,

\footnotetext{
${ }^{4}$ There has been a recent debate in the macroeconomics literature on asymmetries in the response of output to oil shocks (see e.g. Hamilton (2003, 2011), Herrera, Lagalo and Wada (2011), Kilian and Vigfusson (2011a, 2011b, 2013, 2017), and Ravazzolo and Rothman (2013)). One outcome of this debate has been the development of econometric tools that can be used to estimate models with asymmetries.
} 
depending on the degree of asymmetry, certain policies may not be as beneficial to producers as expected, which in turn could also carry adverse effects for consumers (Awokuse and Wang, 2009). Lastly, the impact of government intervention targeting potential inefficiencies in the U.S. beef market could have unexpected welfare and income distribution effects depending on the presence or absence of asymmetry.

\section{Related Literature}

This is not the first paper to test for asymmetric adjustment in the U.S. beef market. ${ }^{5}$ The closest to the present, Goodwin and Holt (1999, hereafter GH), investigated price transmission asymmetries using weekly data. They concluded that there was asymmetric price transmission, with unidirectional causal flow from farm to wholesale to retail markets, but the magnitude of asymmetry following a particular shock was not economically significant.

The primary difference between the present study and GH is the methodology. The generalized impulse response function analysis in GH can be used to make forecasts, identify deviations from linearity in a system of equations, and characterize persistence in the data, but it was not designed to do impulse response function analysis, at least not in the sense that the term is commonly used in the structural VAR literature. ${ }^{6}$ We apply the methodology in Kilian and Vigfussion (2011), which builds on the generalized impulse response function analysis in Koop, Pesaran and Potter (1996), to estimate the responses of retail, wholesale, and farm beef prices to shocks to upstream and downstream beef prices. The impulse response functions we report are not conditioned on an assumption of a particular choice for recent price behavior or a particular set of future shocks. ${ }^{7}$ See Kilian and Vigfusson (2011) for

\footnotetext{
${ }^{5}$ Related studies that we do not discuss here include von Cramon-Taubadel (1998), and Peltzman (2000).

${ }^{6}$ As Kilian and Vigfusson (2011) explain, "Such responses may be useful in characterizing the persistence of the data, but they are devoid of any economic interpretation."

${ }^{7}$ As Kilian and Vigfusson explain, "Thus, nonlinear impulse response functions must be computed for a given shock as the average of impulse response functions obtained using alternative initial conditions. This point is well known (see, e.g., Gallant et al., 1993; Koop et al., 1996) ..."
} 
further discussion of this point.

Our methodology also differs from GH along two other dimensions. First, we present confidence intervals on the estimated impulse response functions. Second, we allow for asymmetry in the response to deviations from the long-run relationship between the variables, using a threshold cointegration model as in GH, but also in the short run response to price changes, as in the literatures on gasoline pricing (see e.g., Borenstein, Cameron and Gilber, 1997), the effects of oil shocks on the macroeconomy (see e.g., Hamilton, 2011; Kilian, 2008; Kilian and Vigfusson, 2011), and other markets (Peltzman, 2000). The threshold cointegration model is intuitively appealing - a price series might return to equilibrium at a different speed depending on the sign and magnitude of its deviation from its long run equilibrium value. It is nonetheless difficult to justify the assumption that this is the only type of asymmetry in the system. Among other things, the requirement that asymmetries have to take a threshold cointegration form rules out asymmetries when the price series are stationary, or when they are nonstationary but not cointegrated. The theoretical justification for such a restrictive assumption is unclear.

A final difference between this paper and $\mathrm{GH}$ is that our dataset is taken entirely from the post-Livestock Mandatory Reporting Act regime. GH was published in 1999, and as a result, they used much older data in their analysis. In addition to the differences in methodology described above, a reassessment of their results using recent data is warranted.

Frey and Manera (2007) and Meyer and von Cramon-Taubadel (2004) provide comprehensive surveys of the empirical literature on agricultural commodity price asymmetry, classifying and comparing heterogeneous studies in terms of econometric models employed, type of asymmetries tested and findings. More recent studies dealing with asymmetric price transmission in the U.S. beef supply chain are Boetel and Liu (2010), Emmanouilides and Fousekis (2015), Fousekis, Katrakilidis and Trachanas (2016), and Chung, Rushin and Sarathkal (2017). 
Boetel and Liu (2010) examined wholesale and retail price relationships in the beef and pork markets by accounting for possible structural breaks in the data. Their results revealed the presence of asymmetric price responses in the beef market distribution chain. However, they worked with a reduced-form model, restricted the analysis to a threshold cointegration model, and conditioned on a specific history and set of future shocks when computing impulse response functions. Therefore, their findings are subject to the criticisms of Kilian and Vigfusson (2011). Emmanouilides and Fousekis (2015) used a statistical copula approach to assess the degree of price dependency along farm and wholesale, and wholesale and retail beef prices using data from 2000 to 2013. Their results provide evidence of positive asymmetric price transmissions, mainly between farm and wholesale prices, but they do not provide information about the magnitude of asymmetry, nor the speed of adjustment in the price transmission process, and their study was limited to performing hypothesis tests.

Fousekis, Katrakilidis and Trachanas (2016) applied a nonlinear autoregressive distributed lag model to monthly U.S. beef price data and found evidence of price asymmetry from farm to wholesale and from wholesale to retail markets. Chung, Rushin and Sarathkal (2017) contrasted price transmissions before and after the implementation of the Livestock Mandatory Reporting Act and found limited evidence of increasing asymmetric price responses in the post-Act period. The four aforementioned studies have advanced the vertical price transmission literature by applying more complex methods. However, these studies have also relied on BLS retail price data to conduct their analysis.

In the literature, concerns exist regarding the quality of traditional data series used in economic analysis. More specifically, the use of BLS retail price series has long been criticized. In 1978, Geithman and Marion published a critique of the use of BLS data for market structure-price analysis. They argued that bias in the BLS price data confounded true market structure-price relationships and adjustments in sampling and reporting procedures are needed to make the data more useful. Despite frequent revisions in price data collection and measurement methodologies, the BLS has not developed a methodology to correct for 
potential bias in reported food prices. More recent work by Hausman and Leibtag (2009) showed that the consumer price index (CPI) for food- at-home, calculated using price data collected by BLS, overstates food price inflation. During 1998 to 2001 about a 15 percent upward bias was present in the CPI for food-at-home, which Hausman and Leibtag attributed to the increasing share of food purchases made at alternative (non-traditional) retail stores such as supercenters, mass merchandisers and club stores.

Few studies have compared advantages and shortcomings of using scanner price data versus BLS retail price data. Hahn, Perry and Southard (2009), used dynamic-adjustment, state-space models to assess the relative value of the two data series in representing the national average retail price and forecasting near-term meat market conditions. Using monthly data from January 2001 to August 2005 (56 observations), they also analyzed wholesale-retail price relationships (including speed of adjustment) in beef, pork, broiler, whole chickens and whole frozen turkeys. Scanner data contributed little to the price analysis for four of the five meat products, particularly attributed to timing issues - scanner data was available with a 7-8 week lag, whereas BLS data were generally available 12-20 days after the end of the month of interest. Lensing and Purcell (2006) analyzed differences between the means and variances of BLS and scanner quantity-weighted monthly average prices for beef and estimated elasticities using a single equation quantity-dependent demand function. Scanner quantity-weighted monthly average retail prices for five of six beef items were lower than BLS prices. Scanner quantity-weighted prices also had a higher variance for five of six retail items. In addition, BLS prices were greater than scanner prices and resulted in more elastic own-price elasticity estimates.

Previous studies have also examined asymmetric price transmissions in different markets using BLS retail price data. For example, Gervais (2011) tested for nonlinearities in the long- and short-run price relationship in the hog/pork supply chain by applying a smooth transition cointegration model. Results provided evidence of nonlinearities in the farm-to-retail price relationship. Focusing on dairy markets, Awokuse and Wang (2009) found 
that prices at the producer-retail levels portray an asymmetric behavior of in butter and fluid milk markets, but not in the cheese market using threshold error correction models. More recently, Kim and Ward (2013) examined vertical price transmissions within 100 commodities in the food sector and found evidence of asymmetric behavior in all but three of the five food groups considered in the analysis (i.e., grains, red meats, poultry and eggs, and dairy, but not fruits and vegetables). The limitations of BLS retail prices may have important implications on the validity of price asymmetry results from previous work. The current study intends to shed some light on this issue.

\section{Methods}

\subsection{A Model of Beef Prices}

Our baseline model is a threshold vector error correction (TVEC) model. Let $R_{t}, W_{t}$ and $F_{t}$ be respectively the retail, wholesale, and farm prices of beef at time $t$. The structural form of our TVEC model can be written as:

$$
\begin{aligned}
\Delta R_{t}= & a_{10}+I_{t} b_{11}^{+} E C T_{t-1}+\sum_{k=1}^{p} c_{12, k}^{+} \Delta R_{t-k}+\sum_{k=0}^{p} c_{13, k}^{+} \Delta W_{t-k}+\sum_{k=0}^{p} c_{14, k}^{+} \Delta F_{t-k} \\
& +\left(1-I_{t}\right) b_{11}^{-} E C T_{t-1}+\sum_{k=1}^{p} c_{12, k}^{-} \Delta R_{t-k}+\sum_{k=0}^{p} c_{13, k}^{-} \Delta W_{t-k}+\sum_{k=0}^{p} c_{14, k}^{+} \Delta F_{t-k}+e_{1, t}
\end{aligned}
$$

$$
\begin{aligned}
\Delta W_{t}= & a_{20}+I_{t} b_{21}^{+} E C T_{t-1}+\sum_{k=0}^{p} c_{22, k}^{+} \Delta R_{t-k}+\sum_{k=1}^{p} c_{23, k}^{+} \Delta W_{t-k}+\sum_{k=0}^{p} c_{24, k}^{+} \Delta F_{t-k} \\
& +\left(1-I_{t}\right) b_{21}^{-} E C T_{t-1}+\sum_{k=0}^{p} c_{22, k}^{-} \Delta R_{t-k}+\sum_{k=1}^{p} c_{23, k}^{-} \Delta W_{t-k}+\sum_{k=0}^{p} c_{24, k}^{+} \Delta F_{t-k}+e_{2, t}
\end{aligned}
$$




$$
\begin{gathered}
\Delta F_{t}=a_{30}+I_{t} b_{31}^{+} E C T_{t-1}+\sum_{k=0}^{p} c_{32, k}^{+} \Delta R_{t-k}+\sum_{k=0}^{p} c_{33, k}^{+} \Delta W_{t-k}+\sum_{k=1}^{p} c_{34, k}^{+} \Delta F_{t-k}+ \\
\left(1-I_{t}\right) b_{31}^{-} E C T_{t-1}+\sum_{k=0}^{p} c_{32, k}^{-} \Delta R_{t-k}+\sum_{k=0}^{p} c_{33, k}^{-} \Delta W_{t-k}+\sum_{k=1}^{p} c_{34, k}^{+} \Delta F_{t-k}+e_{3, t}
\end{gathered}
$$

where $\Delta$ is the difference operator; $E C T_{t-1}=R_{t-1}-\gamma_{0}-\gamma_{1} W_{t-1}-\gamma_{2} F_{t-1}$ is the one-period lagged error correction term; the $c_{i j, k}^{+}$apply when the corresponding variable is positive and the $\overline{c_{i j, k}}$ apply when the corresponding variable is negative or less than zero, for equation $i=1,2,3$, variable $j=2,3,4$ and all $k=0, \ldots, p$, where $p$ is the chosen lag length of the VEC model.

$e_{1, t}, e_{2, t}$ and $e_{3, t}$ are uncorrelated structural shocks to the retail, wholesale, and farm beef markets, respectively. The structural TVEC model distinguishes between long-run and short-run price adjustments. The long-run adjustment is determined by $b_{i 1}^{+}$and $b_{i 1}^{-}$and the

short-run adjustment is determined by $c_{i j, k}^{+}$and $c_{i j, k}^{-}$. The indicator function $I_{t}$ is restricted as follows:

$$
I_{t}=\left\{\begin{array}{l}
1 \text { if } E C T_{t-1}>\tau \\
0 \text { if } E C T_{t-1} \leq \tau
\end{array}\right.
$$

where $\tau$ represents the threshold value estimated for the deviation from the long-run equilibrium, which is selected by minimizing the sum of squared errors, with a minimum of 15 percent of the observations in each regime.

\subsection{Threshold Cointegration Tests}

We employ the Enders and Siklos (2001) test for threshold cointegration, which extends Engle and Granger's (1987) two-step estimation approach to include possibly asymmetric 
adjustment to equilibrium. The cointegration relationship between the three price series, each assumed to be integrated of order one, takes the form:

$$
R_{t}=\gamma_{0}+\gamma_{1} W_{t}+\gamma_{2} F_{t}+\varepsilon_{t}
$$

where $\varepsilon_{t}$ measures the deviation from the equilibrium relationship between $R_{t}, W_{t}$ and $F_{t}$. To allow for asymmetric adjustment dynamics, deviations from equilibrium are allowed to follow a threshold autoregressive process:

$$
\varepsilon_{t}=I_{\varepsilon, t} \rho_{1} \varepsilon_{t-1}+\left(1-I_{\varepsilon, t}\right) \rho_{2} \varepsilon_{t-1}+\sum_{k=1}^{P} \delta_{k} \Delta \varepsilon_{t-k}+\mu_{t},
$$

where $\rho_{1}$ and $\rho_{2}$ are the speed of adjustment of $\Delta \varepsilon_{t}$, and the indicator function $I_{\varepsilon, t}$ has a similar specification as equation (4). Cointegration exists if $\rho_{1}<0$ and/or $\rho_{2}<0$, but as the test statistic has a nonstandard distribution due to the data-determined selection of $\tau$, we use the $t_{M a x}$ and $\Phi$ tests. The $t_{\text {Max }}$ statistic is the largest t-statistic associated with the estimated coefficients $\rho_{1}$ and $\rho_{2}$, and the $\Phi$ test is an F-test of the joint hypothesis $\rho_{1}=\rho_{2}=0$. Simulated critical values for both test statistics are provided by Enders and Siklos (2001).

\subsection{Model Identification}

The presence of time $t$ variables as regressors in the system (1)-(3) means there is an identification problem. One way to achieve identification would be to impose the assumption

that the system is recursive, for example, that $c_{22,0}^{+}=c_{22,0}^{-}=c_{32,0}^{+}=c_{32,0}^{-}=c_{33,0}^{+}=c_{33,0}^{-}=0$. Unfortunately, it is hard to justify such an assumption a priori, given the frequency of our data and the information available to market participants.

To identify the system, we apply the heteroskedasticity-based estimator proposed in Rigobon (2003) and subsequently applied to gasoline markets in Bachmeier (2013). If there 
are at least two regimes for the variances of the structural shocks, the system is identified (Rigobon, 2003), and all parameters can be estimated by the generalized method of moments (GMM). The question is how to divide the data into regimes of high and low structural shock variances. We use historical volatilities corresponding to each price series to identify periods of low and high volatility. ${ }^{8}$ Alternatively, we can rely on major market events such as the first case of bovine spongiform encephalopathy (BSE), also known as mad cow disease, reported in the U.S. in December 2003, to identify the regimes. The validity of the regime classification can be formally tested given the estimated structural shock variances. Ultimately, this identification approach delivers the estimates of contemporaneous coefficients $c_{22,0}, c_{32,0}$ and $c_{33,0}$ in system (1)-(3).

\subsection{Symmetry Tests}

After estimating the system (1)-(3), we test for symmetric responses to the structural shocks in two ways. The first approach is to test for equality of the coefficients in the two regimes using an F-test. A test for symmetric adjustment to deviations from the long run equilibrium is a test of $b_{i 1}^{+}=b_{i 1}^{-}$, while a test for symmetric short-run responses to price shocks is a test of $\sum_{k=k_{0}}^{p} c_{i j, k}^{+}=\sum_{k=k_{0}}^{p} c_{i j, k}^{-}$, where $k_{0}=0$ or 1 , for each equation $i=1,2,3$ and variable $j=2,3,4$. A rejection of either hypothesis indicates asymmetry in price adjustment. The downside of testing for equality of coefficients is that a rejection of the null hypothesis of linearity does not provide any information about the speed of adjustment or the direction of asymmetry. The adjustment could be faster or slower after any particular shock. Further, it is possible to reject the null hypothesis of equal slope coefficients, yet still have a symmetric response to shocks at long horizons. That is, asymmetry in the coefficients at one horizon can offset asymmetry in the coefficients at a different horizon. Due to this limitation of coefficient tests, and to directly address the question of symmetry of responses to different price shocks, our second test for symmetry is to calculate impulse response functions by

\footnotetext{
${ }^{8}$ Monthly historical volatility series are calculated using weekly prices.
} 
simulation following the approach outlined in Kilian and Vigfusson (2011).

The impulse response-based test is built on the observation that under the null hypothesis of a symmetric response function, the vector of responses to a positive price shock should be opposite in sign but of the same magnitude as the vector of responses to a negative price shock of the same size. Hence, we can test that all elements of the sum of these two vectors are zero. We compute impulse response functions by simulation using an algorithm similar to that in Kilian and Vigfusson (2011). For example, the algorithm used to estimate the response of the beef retail price to a farm price shock is:

1. Take a block of $p$ consecutive values of $\Delta R_{t}, \Delta W_{t}$ and $\Delta F_{t}$, where $p$ is the lag length of the structural TVEC model. This defines a history $\Omega^{i}$.

2. Define $e_{0}$ to be the shock to the price that is of interest (in this case the shock to $\Delta F_{t}$ ).

3. Define $e_{1, H}$ and $e_{2, H}$ to be vectors holding a draw of $H+1$ values of the identified shocks to $\Delta R$ and $\Delta W$, respectively, where $H$ is the longest horizon for which impulse response functions are calculated.

4. Define $e_{3, H}$ to be a vector holding a draw of $H$ values of the identified shocks to $\Delta F_{t}$.

5. Predict the values of $\Delta R_{t+h}, \Delta W_{t+h}$ and $\Delta F_{t+h}$ for periods $h=0, \ldots, H$, conditional on $\Omega^{i}, e_{1 H}, e_{2 H}$ and $\left(e_{0}, e_{3 H}\right)^{\prime}$, where $e_{0}$ is defined to be either a positive or negative one standard deviation shock to $\Delta F_{t}$.

6. Predict the values of $\Delta R_{t+h}, \Delta W_{t+h}$ and $\Delta F_{t+h}$ for periods $h=0, \ldots, H$, conditional on $\Omega^{i}, e_{1 H}, e_{2 H}$, and $\left(e_{0}, e_{3, H}\right)^{\prime}$, where $e_{0}=0$.

7. Calculate the difference in predicted values of the two variables from steps 5 and 6 . This difference is the impulse response of retail price to a farm price shock of size $e_{0}$, conditional on $\Omega^{i}$. 
8. Steps 1-7 are repeated 1,000 times. The unconditional impulse response function is the average of the output from step 7 across the 1,000 simulations.

9. Perform a fixed-design wild bootstrap (Goncalves and Kilian, 2004) with 500 replications to calculate confidence intervals. ${ }^{9}$ We use the Rademacher pick distribution as suggested by Godfrey (2009).

\section{Data}

Our empirical analysis utilizes monthly beef prices observed from January 2001 through December 2012 (144 observations), as well as weekly beef prices observed from January 2007 through December 2012 (312 observations). Monthly and weekly farm (live cattle) and wholesale (boxed beef) price series were obtained from the Agricultural Marketing Service (USDA-AMS). Farm price is the weighted-five-area average Texas-Oklahoma, Kansas, Nebraska, Colorado, and Iowa-Minnesota live steer and heifer price for all grades. Wholesale price is the weighted-average of Choice and Select boxed beef cutout value for 600-900 lbs. carcasses. The Economic Research Service (USDA-ERS) has available monthly retail beef prices reported by the BLS. ${ }^{10}$ The BLS retail price used is the traditional simple-average retail price for all grades beef. All prices are in cents per pound.

To test whether the results are sensitive to the type of data used in the analysis of asymmetric price transmissions, we also estimate our structural TVEC model (system (1)-(3)) using scanner quantity-weighted retail prices. Scanner data are compiled by USDA-ERS and Freshlook and were obtained from the National Cattlemen's Beef Association. These prices are in both monthly and weekly frequency and also correspond to all grades of beef. ${ }^{11}$ In total,

\footnotetext{
${ }^{9}$ The wild bootstrap accounts for possible conditional heteroskedasticity of the error term.

${ }^{10}$ The BLS retail price for beef is only available on a monthly frequency.

${ }^{11}$ The scanner price data is only available beginning in January 2001 (monthly data) and January 2007 (weekly data), and was consistently collected until December 2012, thus limiting the period considered in this analysis.
} 
three (trivariate) structural TVEC models are estimated using: monthly BLS, wholesale and farm prices; monthly scanner, wholesale and farm prices; and weekly scanner, wholesale and farm prices.

Figure 1 contains the plot of monthly BLS and scanner beef retail price series. There are apparent differences between the two price series. The mean of scanner prices for all grades of beef is 352.9 cents/lb. and the mean of BLS prices for all grades of beef is 375.2 cents/lb. According to the difference in means test, BLS prices are on average $6 \%$ higher than scanner prices $(\mathrm{p}$-value $<0.01)$. In addition, a test of equality of variances indicates that the variance of detrended scanner prices (20.5) is larger than the variance of detrended BLS prices (14.4) (p-value $<0.01)$.

Unit root tests did not reject nonstationarity of any of the price series. ${ }^{12}$ In addition, we conducted the Enders and Siklos's (2001) $t_{\text {Max }}$ and $\Phi$ tests for threshold cointegration on each structural TVEC model to account for possible asymmetric adjustments to deviations from the long-run equilibrium (Table 1). This test was performed in two steps. First, equation (5) was estimated by OLS for each model. Then, equation (6) was estimated using the residuals from equation (5) and the specification of equation (4) where the value of $\tau$ was set equal to zero $(T C 1)$ and different from zero $(T C 2)$, in which case the threshold value was estimated by grid search method as described in Chan (1993). Looking at the results in Table 1, we reject the null hypothesis of no cointegration at the 0.05 significance level in all cases, whether or not the threshold value is assumed to be zero. We conclude that there is a long-run equilibrium relationship characterized by asymmetric adjustment, and proceed with a structural TVEC model.

\footnotetext{
${ }^{12}$ We used an ADF test with lag length chosen by the AIC.
} 


\section{Results and Discussion}

\subsection{Baseline Model}

Our baseline model is estimated using the natural logarithms of monthly retail BLS, wholesale and farm prices in first differences (Monthly $B L S$ ). We then check the sensitivity of these results by estimating two additional structural TVEC models, one using monthly scanner, wholesale and farm prices (Monthly Scanner), and the other using weekly scanner, wholesale and farm prices (Weekly Scanner). The data in both models are also expressed in natural logarithms and first differences.

The estimation of structural TVEC models using monthly data requires the identification of contemporaneous effects. ${ }^{13}$ We used the method proposed by Rigobon (2003), which exploits the heteroskedasticity of structural shocks. Two regimes, one of high volatility and one of low volatility, were identified using historical volatilities derived from each price series. First, a structural break test was conducted in the historical volatility series to find significant breaks and define the regime windows more precisely. We applied the Bai and Perron (2003) test because it allows us to identify multiple breaks. We allowed up to 5 breaks and used a trimming of at least 0.15 , so each segment has a minimum of 15 observations. The best number of breaks was selected based on the Bayesian Information Criterion (BIC). Results from this test indicate the presence of one high volatility regime from February 2003 to June 2004, most likely caused by the BSE discovery. Thus, we define this period as the high volatility regime, and the remaining as the low volatility regime. Coefficients of contemporaneous effects and variances of structural shocks were estimated by GMM, with standard errors and confidence intervals computed using a fixed-design wild bootstrap (Goncalves and Kilian, 2004).

We reject the null hypothesis that the system estimated using monthly data is

\footnotetext{
${ }^{13}$ Causality from farm to wholesale and retail markets using weekly data has been discussed in previous research (Goodwin and Holt, 1999).
} 
recursive with a causal direction from farm to wholesale to retail prices, as previously assumed in models estimated using weekly data. ${ }^{14}$ Wholesale and farm prices affect retail prices contemporaneously, but not vice versa. Therefore, we set $c_{22,0}^{+}=c_{22,0}^{-}=0$ and $c_{32,0}^{+}=c_{32,0}^{-}=0$. We also find that farm and wholesale prices affect each other at time t. Because this is a bi-directional effect, the system cannot be estimated without further assumptions. Therefore, we assume that the contemporaneous effects of farm and wholesale prices on each other are symmetric by imposing the estimated values delivered by GMM, so that $c_{24,0}^{+}=c_{24,0}^{-}=0.30$ and $c_{33,0}^{+}=c_{33,0}^{-}=0.76$

The final step in the model specification stage is to impose thresholds. For the short run responses, we set the threshold to zero, so that price increases and decreases have different effects. For the long-run responses, we used two different specifications of equation (4), one where $\tau=0$ and one where $\tau$ was estimated by grid search. Based on the Akaike information criterion (AIC), models estimated with a non-zero $\tau$ are preferred over models estimated with a value of $\tau$ equal to zero. Therefore, we based our analysis on models where the threshold value in equation (4) is different from zero. Furthermore, based on AIC and the evaluation of autocorrelation patterns, the models Monthly BLS and Monthly Scanner were estimated using four lags, and the model Weekly Scanner was estimated using six lags.

Table 2 presents parameter estimates of the equation for retail beef price series, given by (1), for both Monthly BLS and Monthly Scanner models. ${ }^{15}$ T-values were calculated using Newey and West's (1987) HAC consistent standard errors when serial correlation was present in model residuals (i.e., Monthly Scanner model), and the cointegrating vector parameters were estimated using the Engle and Granger (1987) method to maintain consistency with the Enders and Siklos test.

The coefficients on the error correction term $(E C T)$, which measure the immediate adjustment to the deviation from equilibrium, are negative and statistically significant in both

\footnotetext{
${ }^{14} \mathrm{GMM}$ and wild bootstrap estimates are available upon request.

${ }^{15}$ Results from farm and wholesale models (equations 2 and 3 ), and those estimated using weekly data, are not presented but are available upon request.
} 
equations. The coefficients on ECT indicate what portion of the disequilibrium is corrected from one period to the next. The adjustment to disequilibrium is several times larger in the Monthly Scanner model than in the Monthly BLS model. For example, $b_{11}^{+}$, which captures the response of retail price in the high deviation regime, is -0.162 for Monthly BLS and -0.558 for Monthly Scanner. This indicates that the immediate adjustment of scanner retail prices is almost 3.5 times faster than BLS retail prices after a given shock. In other words, retail beef scanner prices are much more responsive to deviations from equilibrium than are BLS retail prices. This is consistent with the notion that scanner prices are more reflective of the prices actually being paid at retail. Any further interpretation of the relationships at alternative market levels is best done by calculating impulse response functions rather than examining individual coefficient estimates.

\section{$5.2 \quad$ Slope-Based Test of Symmetry}

Table 3 presents the results from the slope-based test of symmetry applied to the parameter estimates of each equation in structural TVEC models estimated using the two types of data at different frequencies. The first column identifies the type of data used, followed below by the equation that is being tested. The second and third columns present results from the tests conducted on the short-run and long-run adjustments, respectively. There is evidence of long-run asymmetric price adjustment for only the Monthly Scanner retail price equation. These results indicate that beef prices along the vertical market chain adjust equally to positive and negative changes away from the long-run equilibrium, with one exception. Regarding the short-run price adjustment, we fail to reject the null hypothesis of symmetry at the 0.05 significance level in the Monthly Scanner retail price equation. As noted above, while this test finds evidence of nonlinearity in one of the estimated equations, it does not provide information about the source of asymmetry (e.g., whether asymmetry is due to the farm or wholesale price adjustments, to its own shocks, or to more than one shock), the 
form that the asymmetry takes, or the speed of adjustment following positive and negative shocks to one of the variables in the model. The nonlinear impulse response function analysis proposed by Kilian and Vigfusson (2011) is able to provide a more meaningful summary of the estimated models.

\section{$5.3 \quad$ Impulse Response-Based Test of Symmetry}

Results from the impulse response-based test of symmetry are plotted in Figures 2-4. Each row in these Figures corresponds to responses of shocks to farm, wholesale and retail prices, respectively, expressed in percentage changes since variables in each TVEC model are in log-differences. Figure 2 depicts cumulative impulse responses to a one-standard deviation positive and negative shock in farm, wholesale, and retail (BLS and scanner) prices. ${ }^{16}$ For example, the size of the initial farm price shock is $2.4 \%$ in the model estimated using BLS retail price data (first row).

The implied responses in Figure 2 to shocks of typical magnitude are very symmetric in some cases, while present some degree of asymmetry in others. However, responses estimated using scanner data seem to be more symmetric than those estimated using BLS data. From this figure, we can obtain information related to the speed of adjustment in price transmissions. The plots indicate that price responses adjust as fast following positive or negative shocks, providing evidence that the speed of adjustment in price transmissions is fairly symmetric regardless of the type of data used. However, it takes longer for the system to adjust to farm and wholesale price shocks, compared to shocks on retail prices. For example, it can take up to 10 months for wholesale and retail prices to adjust to farm price shocks, whereas responses to retail market shocks are generally complete after 7 months, suggesting that farm and wholesale price shocks have a longer effect in the beef supply chain.

Figure 2 also provide information regarding the responsiveness of scanner and BLS

\footnotetext{
${ }^{16}$ Note that cumulative responses to negative shocks are shown as a mirror image to facilitate comparison.
} 
retail beef prices to changes in upstream prices. This figure shows that monthly retail scanner prices are more responsive to farm and wholesale prices changes than monthly retail BLS prices. For example, after a $2.7 \%$ shock to wholesale prices, the maximum reaction in BLS retail prices is $1.3 \%$ increase or decrease depending on the sign of the shock. However, scanner retail prices have a reaction of as large as $2 \%$ increase or decrease after the same shock (second row). This result provides more evidence in favor of scanner prices because it shows that they are more reflective of reality.

In Figures 3-4, the solid line is the summation of positive and negative IRF. The null hypothesis of symmetry is rejected if corresponding confidence intervals do not contain 0. Therefore, our impulse response based test is based on the statistical significance of the solid line depicted in each plot. Confidence intervals are computed using the fixed-design wild bootstrap estimates, and are represented by the dashed lines.

Figures 3-4 provide information regarding the magnitude of price adjustments derived from models estimated using BLS and Scanner retail price data, respectively. Comparing price responses following a shock to farm price in, we reject the null hypothesis of symmetry at the 0.05 significance level in one case. This case shows a negative asymmetric response in BLS retail prices during the first and second month after the shock (Figure 3, first row). That is, after a $2.40 \%$ positive shock to farm price, retail prices increase $0.22 \%$ percent. In contrast, after a $2.40 \%$ negative shock, retail prices fall by $0.38 \%$ percent, two months after the shock. Economically, this magnitude of asymmetry of $0.16 \%$ is small compared to the size of the farm shock. This result is not robust to other type or frequency of data. That is, both structural TVEC models estimated using monthly and weekly scanner data fail to reject the null hypothesis of symmetry (Figure 4 , first row). ${ }^{17}$

Focusing on price responses following a shock to wholesale price, farm, wholesale and retail prices show a statistically significant and positive asymmetric response to this

\footnotetext{
${ }^{17}$ Plots derived from models estimated using weekly scanner data are not presented but are available upon request.
} 
shock (Figure 3, second row). Following a 2.70\% increase in wholesale price, wholesale prices increase by $3.50 \%$, but decrease by $2.56 \%$ three months after a negative shock of the same magnitude. Similarly, farm prices increase $2.95 \%$ when the wholesale shock is positive, but decrease $1.95 \%$ when the wholesale shock is negative, three months after the shock. Contrary to previous research, this finding suggests that prices received by beef cattle producers adjust more fully to wholesale price increases than decreases. Moreover, four months after the wholesale shock, retail beef prices increase $1.3 \%$, but decrease $0.88 \%$. This indicates that price increases at the retail level, caused by increases in wholesale prices, are transmitted more fully to consumers than price decreases. It also signals a relative advantage of retailers over meat packers and processors, because their gross margin tends to remain the same after a wholesale price increase, whereas it expands after a wholesale price decrease. On the contrary, results derived from scanner prices show symmetric responses following a shock to the wholesale price (Figure 4, second row). The same applies to responses derived from weekly data.

Following shocks to the retail price (Figure 3, third row), we fail to reject the null hypothesis of symmetry in all cases, except one. BLS retail prices react asymmetrically to own price shocks. That is, following a $0.9 \%$ positive and negative own-price shock, the BLS retail price increases $0.65 \%$ and decreases $0.52 \%$, respectively. This result, however, is not robust to either type or frequency of data (Figure 4, third row). Altogether these results show evidence of how different types of data can lead to different conclusions about asymmetric price transmissions.

Table 4 summarizes the results from the impulse response-based test of symmetry in structural TVEC models. Interestingly, asymmetric responses along the beef market chain are only found in models that use BLS retail price data. ${ }^{18}$ In particular, retail prices respond asymmetrically to shocks in farm and wholesale prices, as well as own-price shocks. In

\footnotetext{
${ }^{18}$ These results are robust to using a recursive identification scheme, where the direction of causality flows from farm to wholesale and retail markets.
} 
addition, results obtained from models that use scanner retail price data are robust to the use of different data frequency (i.e., monthly and weekly). However, they are not consistent with results found using the slope-based test of symmetry (table 3). This finding corroborates Kilian and Vigfusson's (2011) argument suggesting that slope-based tests are misleading when the quantity of interest is the degree to which impulse response functions are asymmetric.

Since our findings differ from those found in the existing literature, an important question is whether it is because of the use of different methodologies, newer data, or a different type of data (scanner prices). To address this question, we applied our weekly model to the data set used by GH. GH found statistically significant, positive asymmetry in the wholesale market after a shock in farm prices using data from 1981 to $1998 .{ }^{19}$ However, the magnitude of this asymmetry was economically small. Results of applying our model to their data reveal asymmetric price transmissions, consistent with their findings. Particularly, wholesale prices responded asymmetrically to shocks in farm prices in all horizons (up to 18 weeks after the shock). ${ }^{20}$ However, the asymmetric responses we found were not as modest. Following a $2 \%$ positive and negative shocks to farm price, the net result is an average increase of $0.56 \%$ in wholesale prices. This assessment suggests that our results do not differ from GH because of methodology differences. Instead our differences in results rest on the use of more recent and/or different data. It is possible that the passage of the LMPR Act has improved the efficiency of beef markets in the U.S. However, a more detailed assessment would be needed to support such a claim. A more plausible explanation is that the scanner price data better reflect the prices consumers actually pay for beef.

\footnotetext{
${ }^{19}$ Although GH did not use BLS data in their study, they found asymmetric price transmissions using weekly average retail prices collected by a private news service that were collected in a similar fashion to how the BLS data are collected (i.e., they were simple averages of listed prices, not volume-weighted prices).

${ }^{20}$ The null hypothesis of symmetry was rejected at the 0.1 significance level.
} 


\subsection{Counterfactual Analysis}

One objection to our failure to reject symmetry with the impulse response function-based tests is that those tests might have low power. ${ }^{21}$ We have evaluated the relevance of this concern via a series of counterfactual exercises. Because our analysis reveals that scanner prices are likely to be more reflective of purchases at the retail level, we focus on the models with scanner price data. The first counterfactual asks how the retail beef price would have behaved over our sample period if the retail price had responded symmetrically to all shocks. Specifically, we modified the estimated equation (1) to be symmetric:

$$
\Delta R_{t}=a_{10}+b_{11} E C T_{t-1}+\sum_{k=1}^{p} c_{12, k} \Delta R_{t-k}+\sum_{k=0}^{p} c_{13, k} \Delta W_{t-k}+\sum_{k=0}^{p} c_{14, k} \Delta F_{t-k}+e_{1, t}
$$

We did this by transforming (1) in two ways:

- Case 1: Impose $b_{11}=\widehat{b}_{11}^{+}, c_{12, k}=\widehat{c}_{12, k}^{+}, c_{13, k}=\widehat{c}_{13, k}^{+}$, and $c_{14, k}=\widehat{c}_{14}^{+}$.

- Case 2: Impose $b_{11}=\widehat{b}_{11}^{-}, c_{12, k}=\widehat{c}_{12, k}^{-}, c_{13, k}=\widehat{c}_{13, k}^{-}$, and $c_{14, k}=\widehat{c}_{14}^{-}$.

The simulation was performed using the identified structural shocks together with the initial values of the retail, wholesale, and farm beef prices at the beginning of our sample. If price asymmetry hurts consumers, the simulated retail price series (which imposes symmetric responses) will be below the historical retail price series. The two price series can be seen in Figure 5. Although there are some differences in the two simulated price series, the general pattern is the same - the retail beef price would have been higher under symmetry. This indicates that to the extent that our tests are unable to detect asymmetry, any asymmetry that does exist has benefited consumers.

We repeated the exercise to see if farmers might be hurt by asymmetry. We imposed

\footnotetext{
${ }^{21}$ We are not aware of any evidence to support that assertion, but test power is always a concern when one fails to reject the null hypothesis.
} 
symmetry on equation (3), which has been identified by imposing $c_{33,0}=0.76$ :

$$
\Delta F_{t}=a_{30}+b_{31} E C T_{t-1}+\sum_{k=1}^{p} c_{32, k} \Delta R_{t-k}+\sum_{k=0}^{p} c_{33, k} \Delta W_{t-k}+\sum_{k=1}^{p} c_{34, k} \Delta F_{t-k}+e_{3, t}
$$

and symmetry is imposed as:

- Case 1: $b_{31}=\widehat{b}_{31}^{+}, c_{32, k}=\widehat{c}_{32, k}^{+}, c_{33, k}=\widehat{c}_{33, k}^{+}$, and $c_{34, k}=\widehat{c}_{34}^{+}$.

- Case 2: $b_{31}=\widehat{b}_{31}^{-}, c_{32, k}=\widehat{c}_{32, k}^{-}, c_{33, k}=\widehat{c}_{33, k}^{-}$, and $c_{34, k}=\widehat{c}_{34}^{-}$.

Similar to the retail case, the simulation was performed using the identified structural shocks together with the initial values of the retail, wholesale, and farm beef prices at the beginning of our sample. If price asymmetry hurts farmers, the simulated farm price series (which imposes symmetric responses) will be above the historical farm price series. Both simulated and actual price series can be seen in Figure 6. Here, we observe two different outcomes the farm beef price would have been lower under case 1, which benefits farmers, and higher under case 2, which harms farmers. It is possible (based on the case 2 results) that there is a harmful form of asymmetry that the impulse-response based test is simply not able to detect.

To understand whether the observed nonlinearities in the wholesale price adjustment influence the behavior of farm prices, we treated the coefficients involving $\Delta W$ separately, resulting in four cases:

- Case 3: $c_{33, k}=\widehat{c}_{33, k}^{+}$.

- Case 4: $c_{33, k}=\widehat{c}_{33, k}^{-}$.

- Case 5: $b_{31}=\widehat{b}_{31}^{+}, c_{32, k}=\widehat{c}_{32, k}^{+}$, and $c_{34, k}=\widehat{c}_{34}^{+}$.

- Case 6: $b_{31}=\widehat{b}_{31}^{-}, c_{32, k}=\widehat{c}_{32, k}^{-}$, and $c_{34, k}=\widehat{c}_{34}^{-}$.

Figure 7 shows that the simulated farm price under symmetry is below the historical farm price when the wholesale price change coefficients are restricted to be symmetric (cases 3 and 
4). However, when only the responses to retail and farm shocks are restricted to be symmetric, the simulated farm price is above the historical farm price (cases 5 and 6). Because this counterfactual analysis allows us to disentangle the total effect of each shock, we are able to confirm that positive asymmetry in the farm market is most likely caused by a nonlinear price adjustment at the wholesale market level. The impulse response-based test failed to show this result most likely because it accounts for the total effect when testing for asymmetry, and does not consider cases 1 and 2 separately, which appear to offset each other.

\section{Conclusions}

Price transmissions among farm, wholesale and retail U.S. beef markets have been a hotly debated topic for a long time. A sizable body of past research has found asymmetric price responses from upstream to downstream markets. A host of potential explanations including market power, information flows, inventory adjustments, menu costs, and empirical methodology employed have been suggested in the literature. We provide new results that update previous studies using more appropriate scanner data to the retail price series evaluated, and employ a new methodology that is designed to allow for the analysis of price asymmetry. Using this novel approach based on the simulation of nonlinear impulse response functions, we test for asymmetric price transmissions in the U.S. beef supply chain.

In general, farm, wholesale, and retail beef prices respond symmetrically to price changes at each market level in models estimated using scanner retail price data at either monthly or weekly frequency. This result reveals an efficient market where price signals transmit vertically in a symmetric fashion up and down the beef value chain. This indicates that farm prices generally respond similarly to downstream market price increases and decreases, and consumer beef prices respond similarly symmetric to upstream price changes. However, we find evidence of asymmetry when models are estimated using BLS retail price series. By the way BLS retail price data are collected, they do not accurately reflect volume- 
weighted sales of beef products. Instead, BLS price data simply reflect posted shelf prices on beef products with limited adjustment for actual volumes of beef that is sold at each price level. In contrast, scanner data reflect volume-weighted prices paid for beef sold across retail UPC scanners. As such, scanner data reflect what consumers actually paid for retail beef products including feature prices which generate larger volume of store sales. Consistent with this is that scanner data beef prices are much more responsive than BLS prices to wholesale beef price changes. The implication is that farm-to-retail margins or the farmer's share of the retail beef dollar calculated using standard BLS retail beef prices are biased and unreliable barometers of farm-to-retail price relationships. This weakness strongly suggests that the use of scanner data for such comparisons would be more reflective of prices actually being paid at retail.

When we disentangle the total effect of a shock to each price series using counterfactual exercises, we find that farm prices tend to respond asymmetrically to wholesale price changes. Interestingly, the type of asymmetry found is positive, indicating that feedlot owners benefit from price changes at the wholesale level. However, this effect is negligible, or cannot be captured by our impulse response-based test, because it is offset by farm price responses at retail and farm levels. Our preferred interpretation is simpler, with the relationship being symmetric, consistent with the hypothesis tests. The counterfactual analysis also suggests that the source of positive asymmetry at the farm level is caused by nonlinearities in the price adjustment of wholesale prices. Beef packers have flexibility to store beef in their coolers when short run wholesale prices decline and as such they can buffer wholesale beef price changes through adjustments to beef inventories. This could make price transmission appear asymmetric, similarly to the notion of captive supplies discussed in Schroeter and Azzam, 2003. The inventory flexibility beef packers have is a probable explanation of the asymmetry observed in wholesale beef price responses to own price shocks.

Our results showing symmetric price responses in the U.S. beef market contrast with those obtained when applying our methodology to a period prior the passage of the LMPR Act. 
Thus suggesting that asymmetry findings do not depend on the methods employed. Perhaps the increased intensity of price reporting under the Act contributed to enhanced vertical market price transmission. However, a more profound assessment is needed to establish the level of causality of the Act on price transmissions, so this remains a question for future research.

The implication of our findings is that concerns voiced over the years about price asymmetry in the U.S. beef market and associated hypotheses regarding potential causes of previously found asymmetry appear less acute when the retail price data used in the empirical analysis is more reflective of actual consumer purchases.

\section{References}

Abdulai, A. 2002. "Using Threshold Cointegration to Estimate Asymmetric Price Transmissions in the Swiss Pork Market." Applied Economics, 34:679-687.

Awokuse, T.O. and X. Wang. 2009. "Threshold Effects and Asymmetric Price Adjustments in U.S. Dairy Markets." Canadian Journal of Agricultural Economics, 57:269-286.

Azzam, A. 1999. "Asymmetry and Rigidity in Retail-Price Transmission: A Theoretical Analysis." American Journal of Agricultural Economics, 81:52-533.

Bachmeier, L. 2013. "Identification in Models of Gasoline Pricing." Economic Letters, $120(1): 71-73$.

Bai, J. and P. Perron. 2003. "Computation and Analysis of Multiple Structural Change Models." Journal of Applied Econometrics, 18:1-22.

Bailey, D. and B.W. Brorsen. 1989. "Price Asymmetry in Spatial Fed Cattle Markets." Western Journal of Agricultural Economics, 14:246-252.

Blinder, A.S. 1982. "Inventories and Sticky Prices: More on the Microfoundation of Macroeconomics." American Economic Review, 72(3):334-348. 
Boetel, B. and D. Liu. 2010. "Estimating Structural Changes in the Vertical Price Relationships in U.S. Beef and Pork Markets." Journal of Agricultural and Resource Economics, 35(2):228-244.

Borenstein, S., A. C. Cameron and R. Gilbert. 1997. "Do Gasoline Prices Respond Asymmetrically to Crude Oil Price Changes?" Quarterly Journal of Economics, 112(1):305-339.

Chan, K.S. 1993. "Consistency and Limiting Distribution of the Least Squares Estimator of a Threshold Autoregressive Model." The Annals of Statistics, 21(1):520-533.

Chung, C., J. Rushin and P. Sarathkal. 2017. "Impact of the Livestock Mandatory Reporting Act on the Vertical Price Rransmission within the Beef Supply Chain." Agribusiness, $34(3): 562-578$.

Crespi, J., T. Saitone and R. Sexton. 2012. "Competition in U.S. Farm Product Markets: Do Long-Run Incentives Trump Short-Run Market Power?" Applied Economic Perspectives and Policy, 34(4):669-695.

Emmanouilides, C. and P. Fousekis. 2015. "Vertical Price Dependence Structures: CopulaBased Evidence from the Beef Supply Chain in the USA." European Review of Agricultural Economics, 42(1):77-97.

Enders, W. and P.L. Siklos. 2001. "Cointegration and Threshold Adjustment." Journal of Business and Economic Statistics, 19:166-167.

Engle, R.F. and C.W. Granger. 1987. "Co-integration and Error Correction: Representation. Estimation and Testing." Econometrica, 55:251-276.

Fousekis, P., C. Katrakilidis and E. Trachanas. 2016. "Vertical Price Transmission in the U.S. Beef Sector: Evidence from the Nonlinear ARDL Model." Economic Modelling, 52:499-506.

Frey, J. and M. Manera. 2007. "Econometric Models of Asymmetric Price Transmission." Journal of Economic Surveys, 21:349-415. 
Gallant, A.R., P. Rossi, and G. Tauchen 1993. "Nonlinear Dynamic Structures." Econometrica, 61:871-907.

Geithman, F. and B. Marion. 1978. "A Critique of the Use of BLS Data for Market Structure-Price Analysis." American Journal of Agricultural Economics, 60:701-705.

Gervais, J. 2011. "Disentangling Nonlinearities in the Long- and Short-Run Price Relationships: An Application to the U.S. Hog/Pork Supply Chain." Applied Economics, 43:1497-1510.

Godfrey, L. 2009. Bootstrap Tests for Regression Models.

Goncalves, S. and L. Kilian. 2004. "Bootstrapping Autoregressions in the Presence of Conditional Heteroskedasticity of Unknown Form." Journal of Econometrics, 123:89120.

Goodwin, B.K. and M.T. Holt. 1999. "Asymmetric Adjustment and Price Transmission in the U.S. Beef Sector." American Journal of Agricultural Economics, 81:630-637.

Hahn, W., J. Perry and L. Southard. 2009. "Comparing Two Sources of Retail Meat Price Data." U.S. Department of Agriculture, Economic Research Service. Retrieved from: http://www.ers.usda.gov/media/178016/err88/_reportsummary.pdf

Hamilton, J. 2003. "What Is An Oil Shock?." Journal of Econometrics, 113(2):363-398.

Hamilton, J. 2011. "Nonlinearities and the Macroeconomic Effects of Oil Prices." Macroeconomic Dynamics, 15:364-378.

Hausman, J. 2003. "Sources of Bias and Solutions to Bias in the Consumer Price Index." The Journal of Economic Perspectives, 17(1):23-44.

Hausman, J. and E. Leibtag. 2009. "CPI Bias from Supercenters: Does the BLS Know that Wal-Mart Exists?" In NBER Chapters. Price Index Concepts and Measurement. National Bureau of Economic Research. University of Chicago Press, 203-231. 
Herrera, A. M., L. G. Lagalo, and T. Wada. "Oil Price Shocks and Industrial Production: Is the Relationship Linear?." Macroeconomic Dynamics, 15(S3):472-497.

Kilian, L. 2008. "Exogenous Oil Supply Shocks: How Big Are They and How Much Do They Matter for the U. S. Economy?" The Review of Economics and Statistics, 90(2):216-240.

Kilian, L. and R. Vigfusson. 2011a. "Are the Responses of the U.S. Economy Asymmetric in Energy Price Increases and Decreases?" Quantitative Economics, 2:419-453.

Kilian, L. and R. J. Vigfusson. 2011b. "Nonlinearities in the Oil Price-Output Relationship." Macroeconomic Dynamics, 15(S3):337-363.

Kilian, L. and R. J. Vigfusson. 2013. "Do Oil Prices Help Forecast US Real GDP? The Role of Nonlinearities and Asymmetries." Journal of Business and Economic Statistics, 31(1):78-93.

Kilian, L. and R. J. Vigfusson. 2017. "The Role of Oil Price Shocks in Causing US Recessions." Journal of Money, Credit and Banking, 49(8):1747-1776.

Kim, H. and R. Ward. 2017. "Price Transmission across the U.S. Food Distribution System." Food Policy, 41:226-236.

Kinnucan, H.W. and O. D. Forker. 1987. "Asymmetry in Farm-Retail Price Transmission for Major Dairy Products." American Journal of Agricultural Economics, 69(2):285-292.

Koontz, S. and C. E. Ward. 2011. "Livestock Mandatory Price Reporting: A Literature Review and Synthesis of Related Market Information Research." Journal of Agricultural and Food Industrial Organization, 9(1):1-33.

Koop. G, M. H. Pesaran and S. M. Potter. 1996. "Impulse Response Analysis n Nonlinear Multivariate Models." Journal of Econometrics, 74:119-147.

Lensing C. and W. Purcell. 2006. "Impact of Mandatory Price Reporting Requirements on Level, Variability, and Elasticity Parameter Estimations for Retail Beef Prices." 
Review of Agricultural Economics, 28:229-239.

Levy, D., M. Bergen, S. Dutta and R. Venable. 1997. "The Magnitude of Menu Costs: Direct Evidence from Large U. S. Supermarket Chains." The Quarterly Journal of Economics, 112(3):791-825.

Meyer, J. and S. Von Cramon-Taubadel. 2004. "Asymmetric Price Transmission: A Survey." Journal of Agricultural Economics, 55(3):581-611.

Miller, D.J. and M.L. Hayenga. 2001. "Price Cycles and Asymmetric Price Transmission in the U.S. Pork Market." American Journal of Agricultural Economics, 83(3):551-562.

Mohanty, S., E.W. Peterson and N.C. Kruse. 1995. "Price Asymmetry in the International Wheat Market." Canadian Journal of Agricultural Economics, 43:355-365.

Newey, W.K. and K.D. West. 1987. "A Simple Positive Semi-definite, Heteroskedasticity and Autocorrelation Consistent Covariance Matrix." Econometrica, 55:703-708.

Peltzman, S. 2000. "Prices Rise Faster than they Fall." Journal of Political Economy, 108(3):466-502.

Ravazzolo, F. and P. Rothman. 2013. "Oil and US GDP: A Real Time Out of Sample Examination." Journal of Money, Credit and Banking, 45(2-3):449-463.

Rigobon, R. 2003. "Identification through Heteroskedasticity." The Review of Economics and Statistics, 85(4):777-792.

Schroeter, J. and A. Azzam. 2003. "Captive Supplies and the Spot Market Price of Fed Cattle: The Plant-Level Relationship." Agribusiness, 19(4):489-504.

U. S. Department of Agriculture, Economic Research Service. 2016. "Statistics and Information, U.S. Beef Industry." Retrieved from: https://www.ers.usda.gov/topics/ animal-products/cattle-beef/statistics-information.aspx

U. S. Department of Agriculture, Grain Inspection, Packers and Stockyards Administration. 2016. "2016 Annual Report, Packers and Stockyards Program." Retrieved from: 
https://www.gipsa.usda.gov/psp/publication/ar/2016_psp_annual_report.pdf

U. S. Department of Justice. 2012. "Competition and Agriculture: Voices from the Workshops on Agriculture and Antitrust Enforcement in our $21^{\text {st }}$ Century Economy and Thoughts on the Way Forward." Retrieved from: http://www.justice.gov/sites/ default/files/atr/legacy/2012/05/16 /283291.pdf

Von Cramon-Taubadel, S. 1998. "Estimating Asymmetric Price Transmission with the Error Correction Representation: An Application to the German Pork Market." European Review of Agricultural Economics, 25:1-18.

Xia, T. 2009. "Asymmetric Price Transmission, Market Power, and Supply and Demand Curvature." Journal of Agricultural \& Food Industrial Organization, 7(1):1-25.

Xia, T., and X. Li. 2010. "Consumption Inertia and Asymmetric Price Transmission." Journal of Agricultural and Resource Economics, 35(2):209-227. 


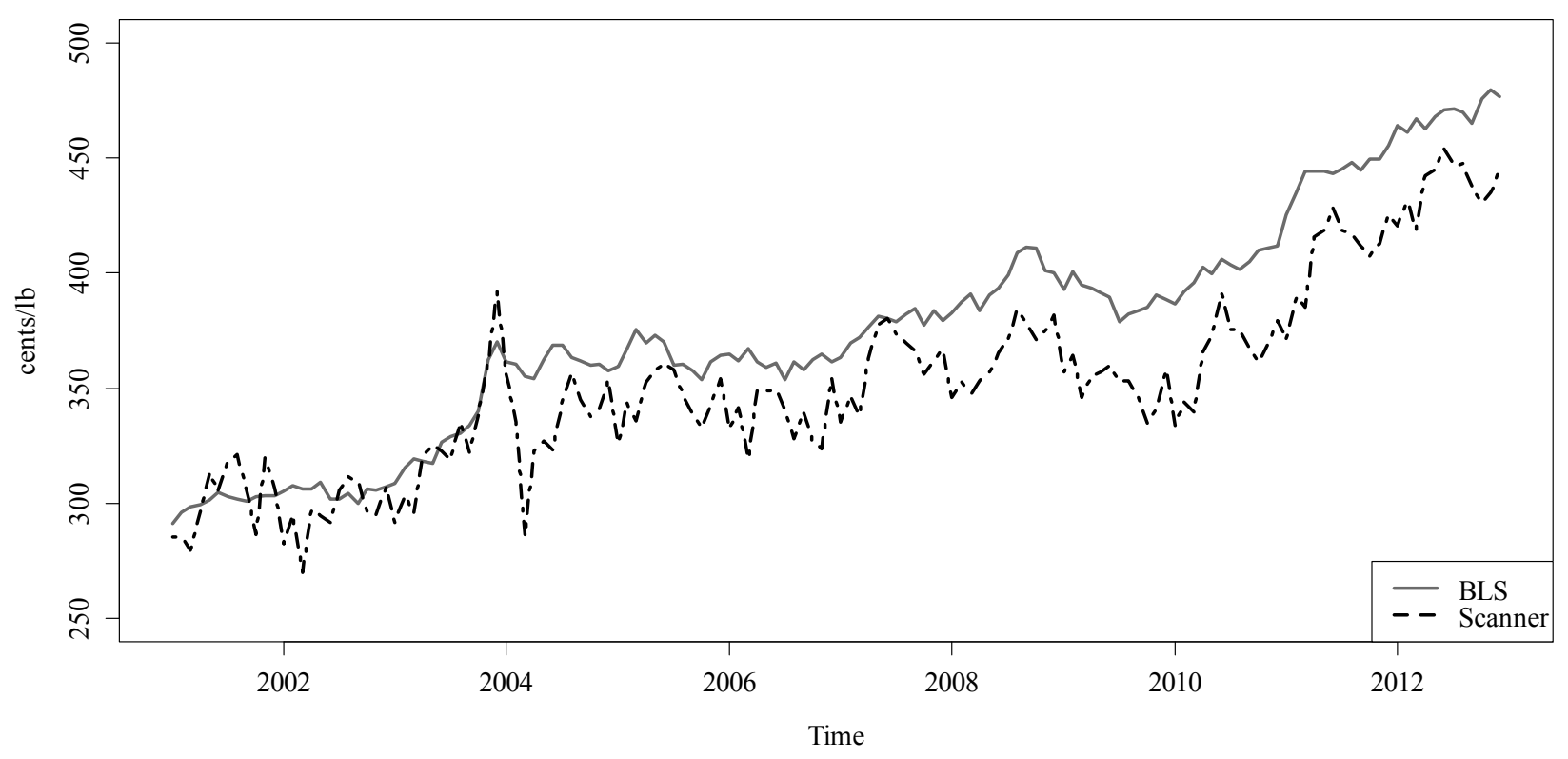

Figure 1. Monthly Retail BLS and Scanner Beef Prices, January 2001- December 2012 
BLS Data

Shock to Farm Price
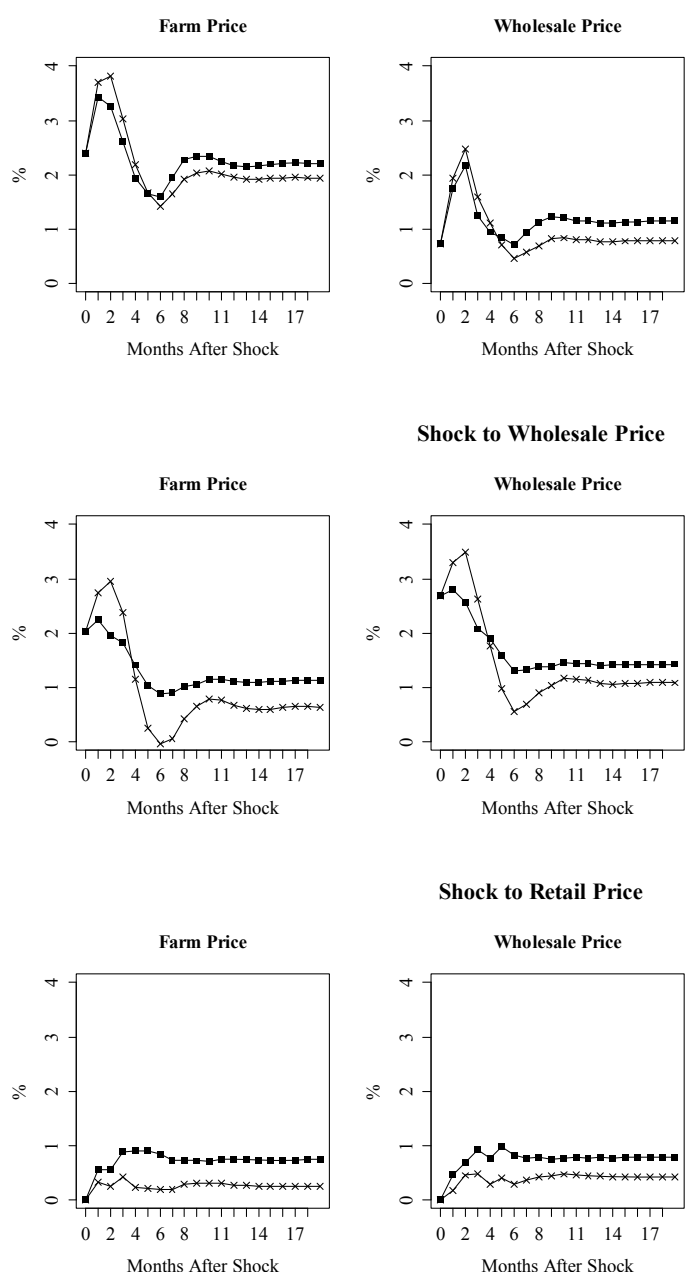

Shock to Wholesale Price

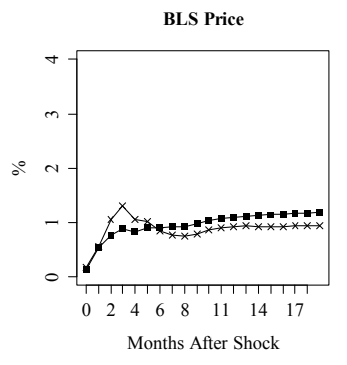

Shock to Retail Price

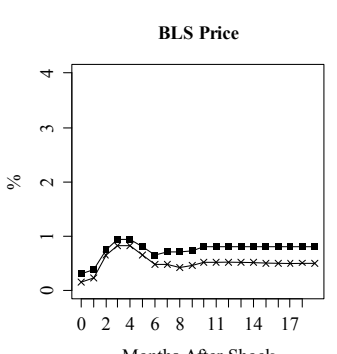

Months After Shock
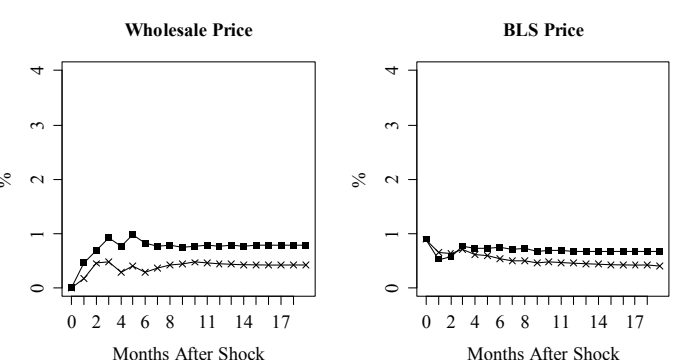
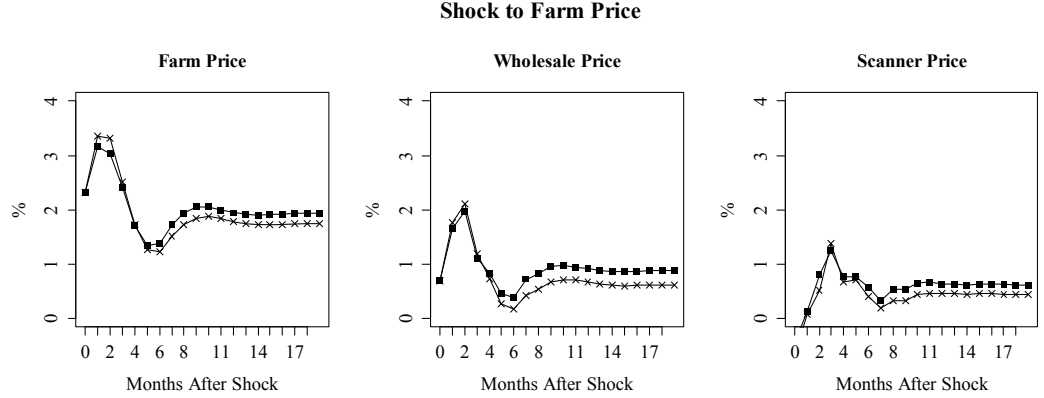

Shock to Wholesale Price
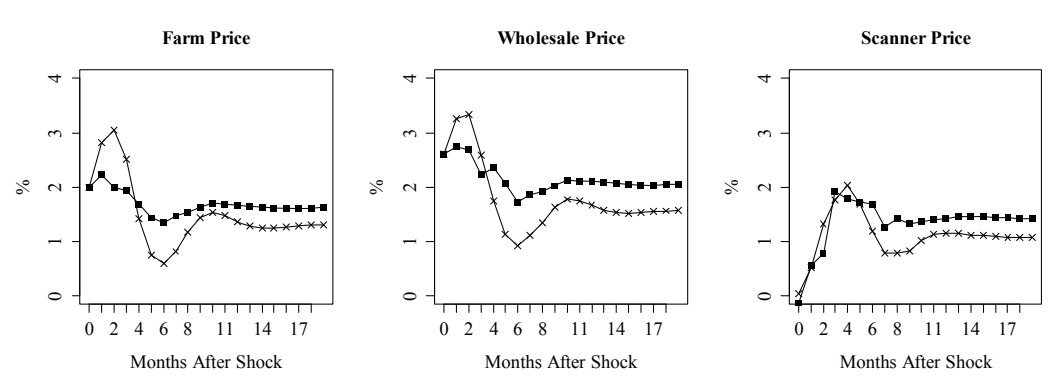

Shock to Retail Price
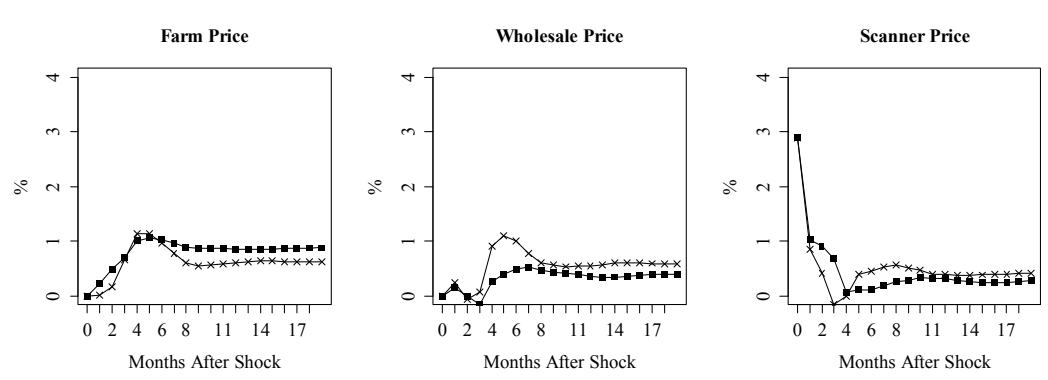

Figure 2. Cumulative Nonlinear Impulse Responses to Positive (×) and Negative (•) "Mirror Images" Shocks. 


\section{Shock to Farm Price}

Farm Price
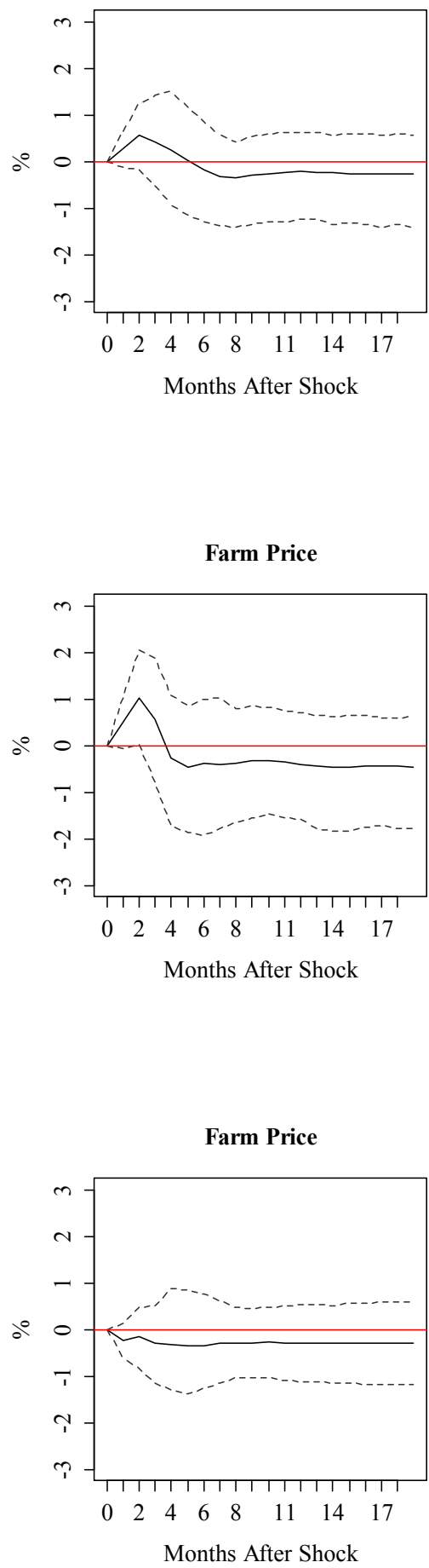

Wholesale Price

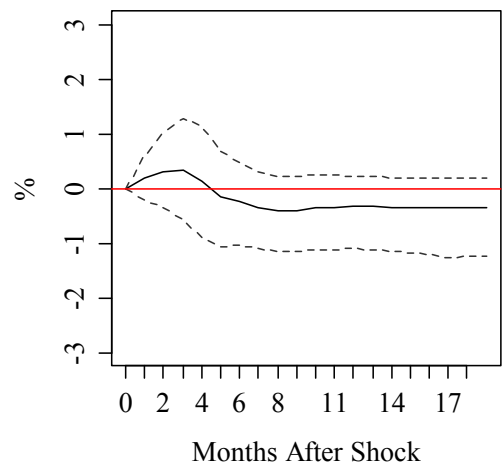

Shock to Wholesale Price

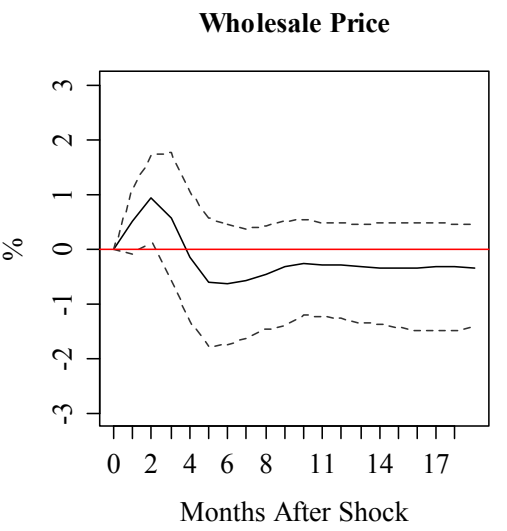

Shock to Retail Price

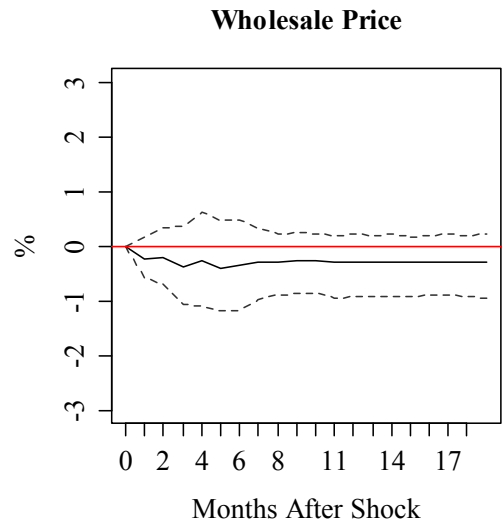

BLS Price

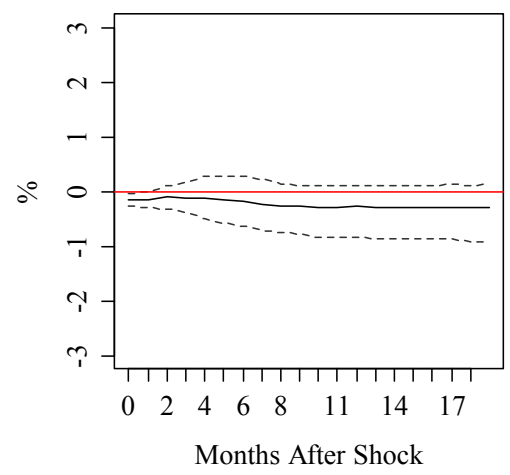

BLS Price

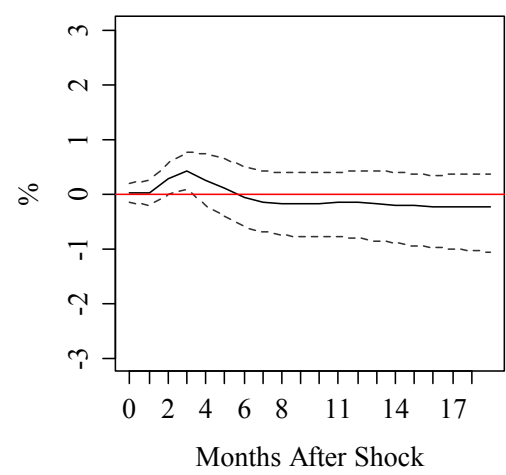

BLS Price

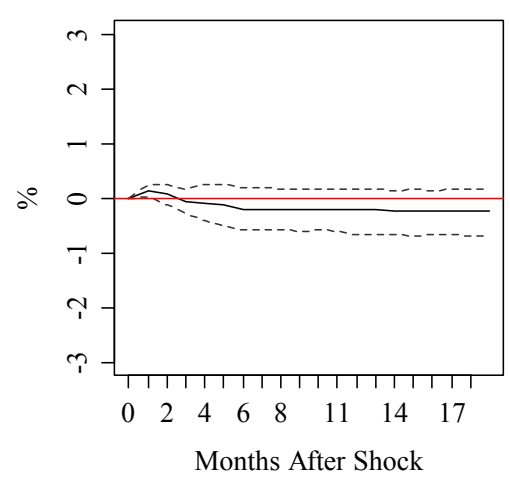

Figure 3. Impulse Response-Based Test of Symmetry - BLS Data 
Shock to Farm Price

Farm Price
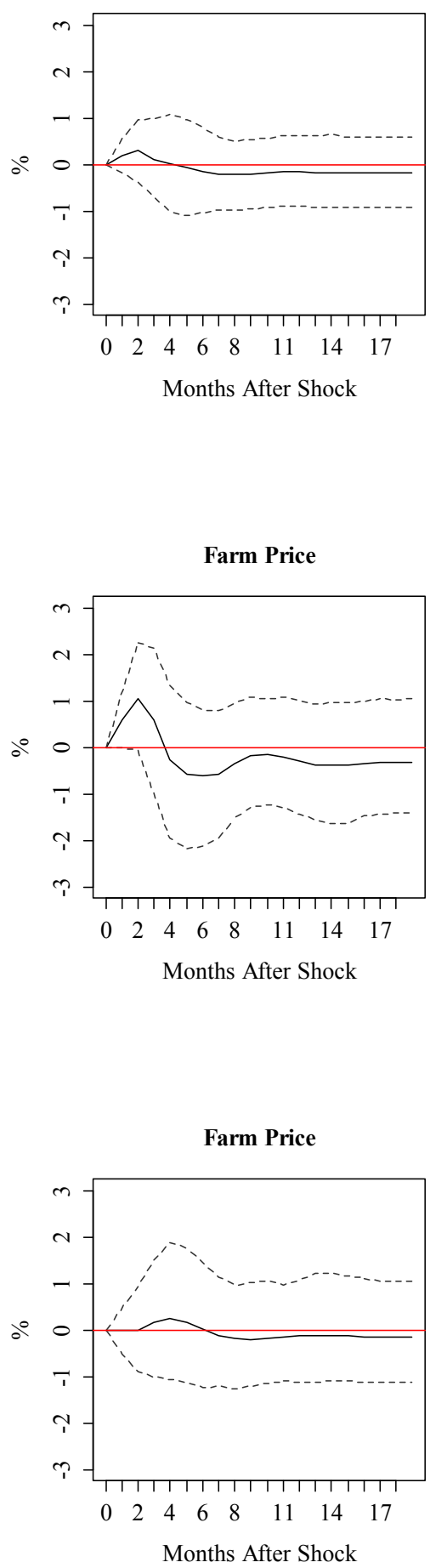

Wholesale Price

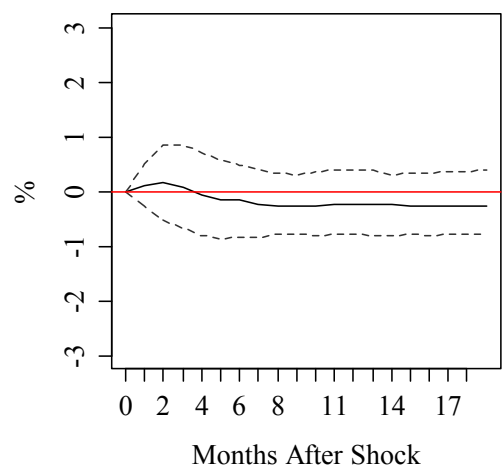

Shock to Wholesale Price

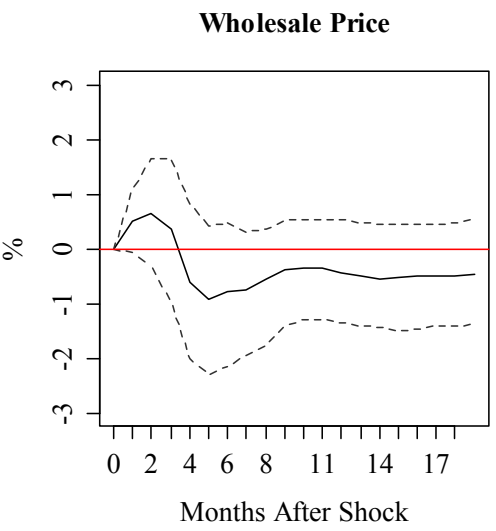

Shock to Retail Price

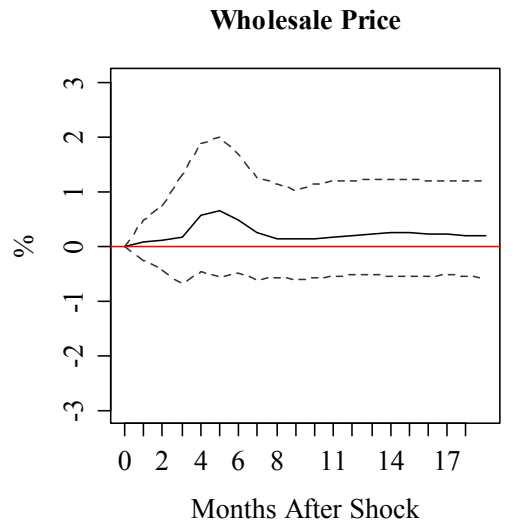

Scanner Price

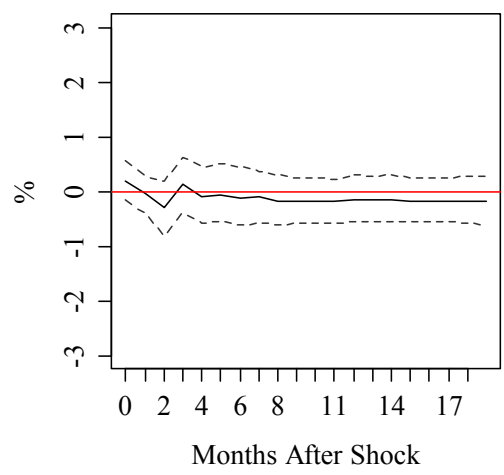

Scanner Price

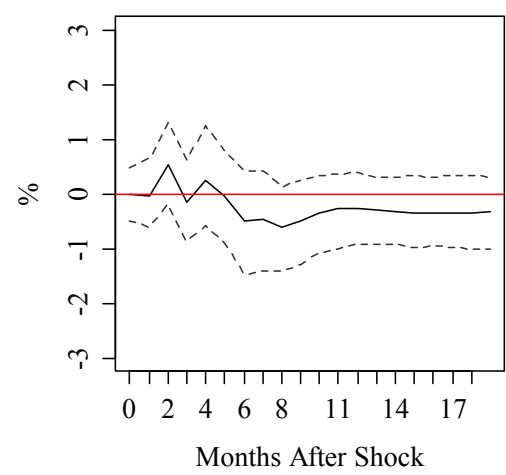

Scanner Price

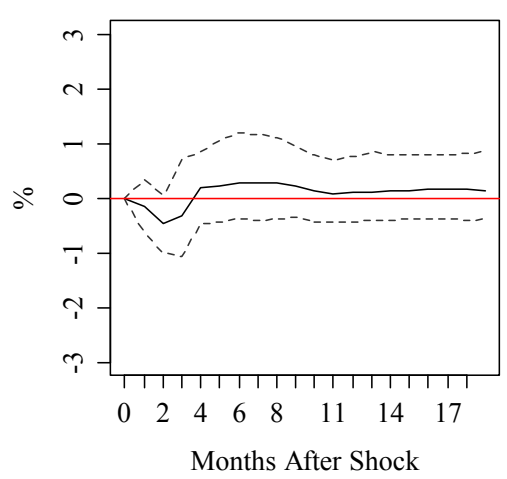

Figure 4. Impulse Response-Based Test of Symmetry - Scanner Data (Monthly) 


\section{Scanner Prices Under Symmetry: Case 1}

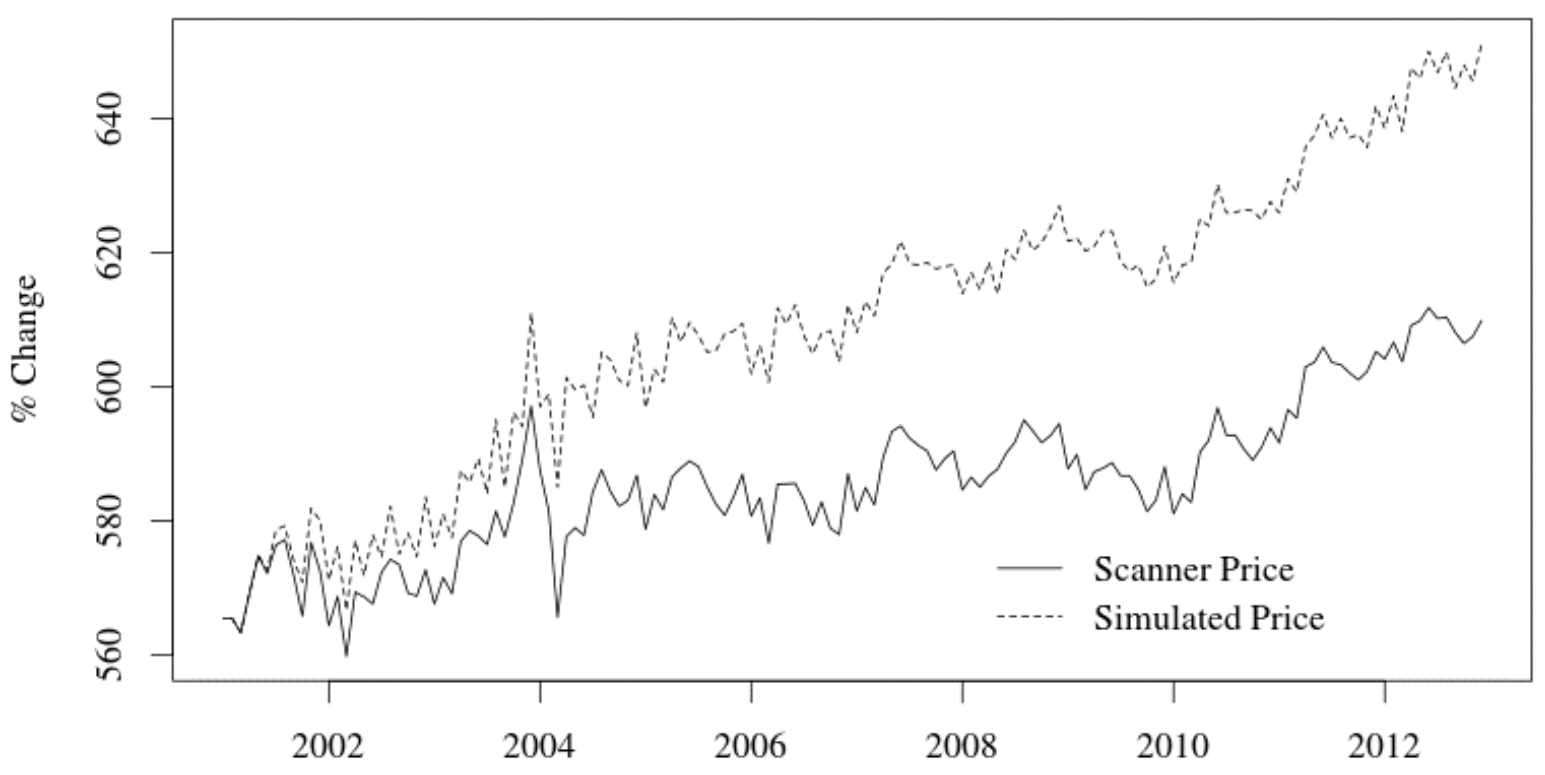

Scanner Prices Under Symmetry: Case 2

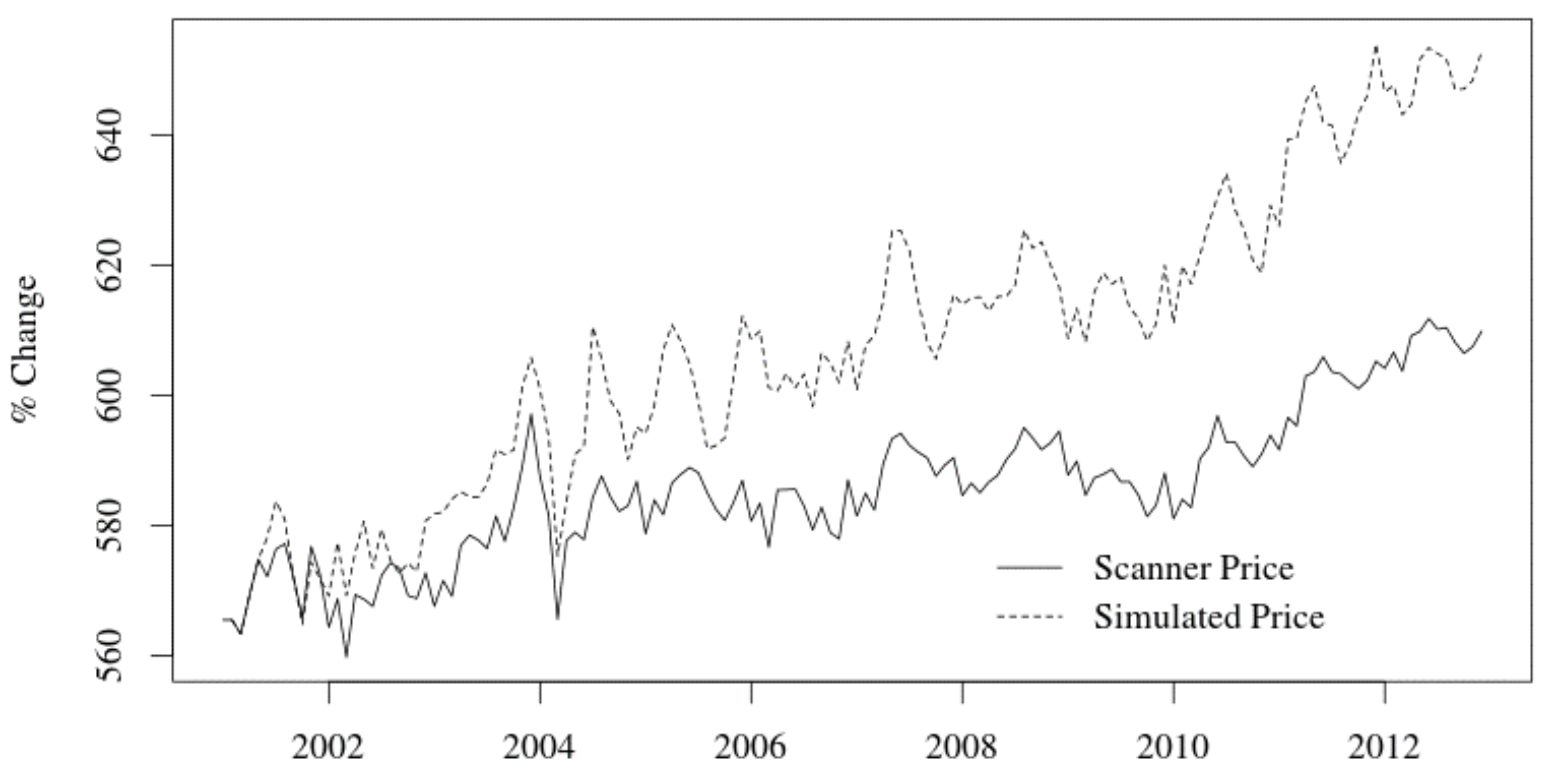

Figure 5. Scanner Prices Counterfactual Analysis 


\section{Farm Prices Under Symmetry, Scanner Data: Case 1}

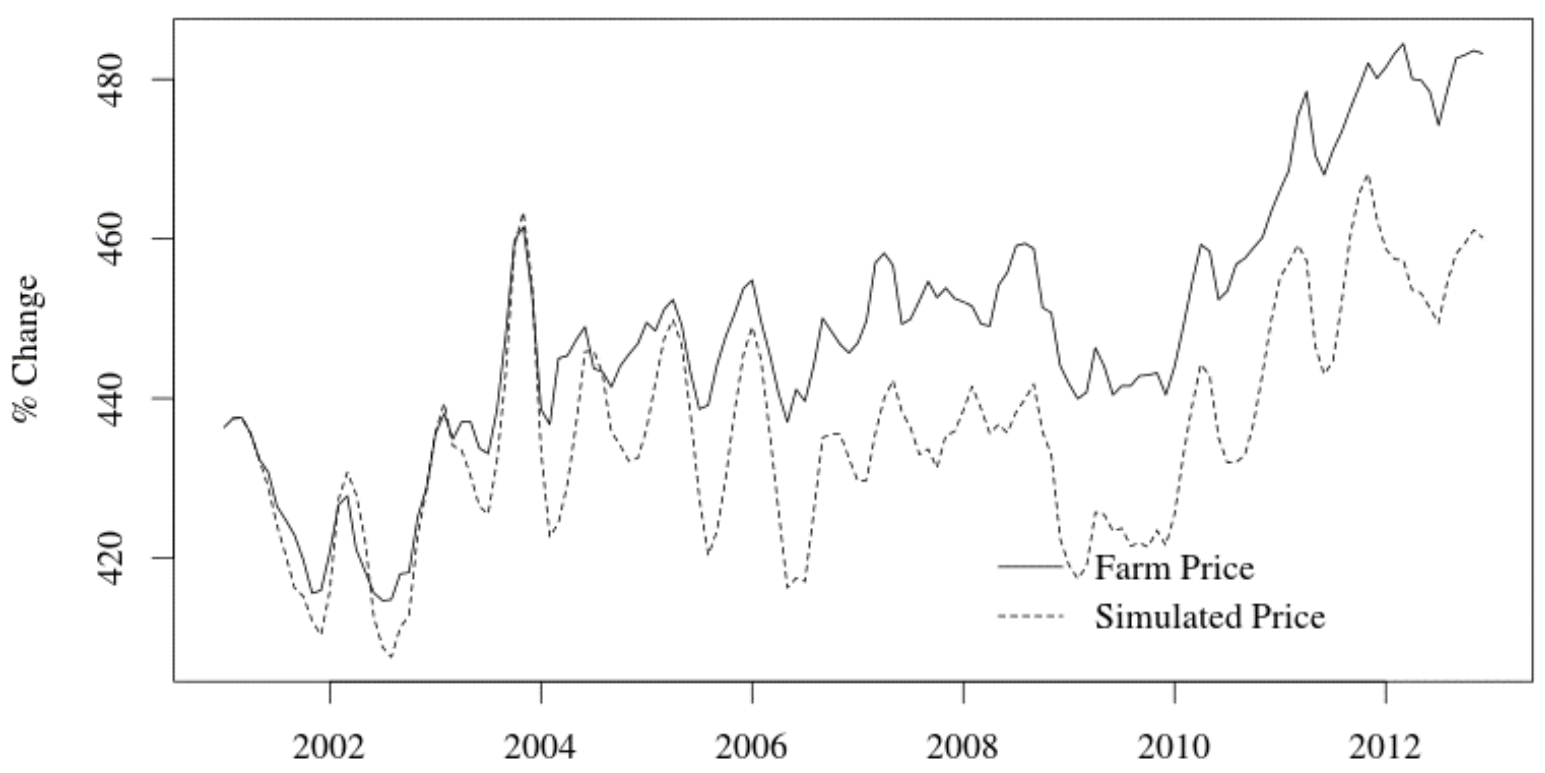

Farm Prices Under Symmetry, Scanner Data: Case 2

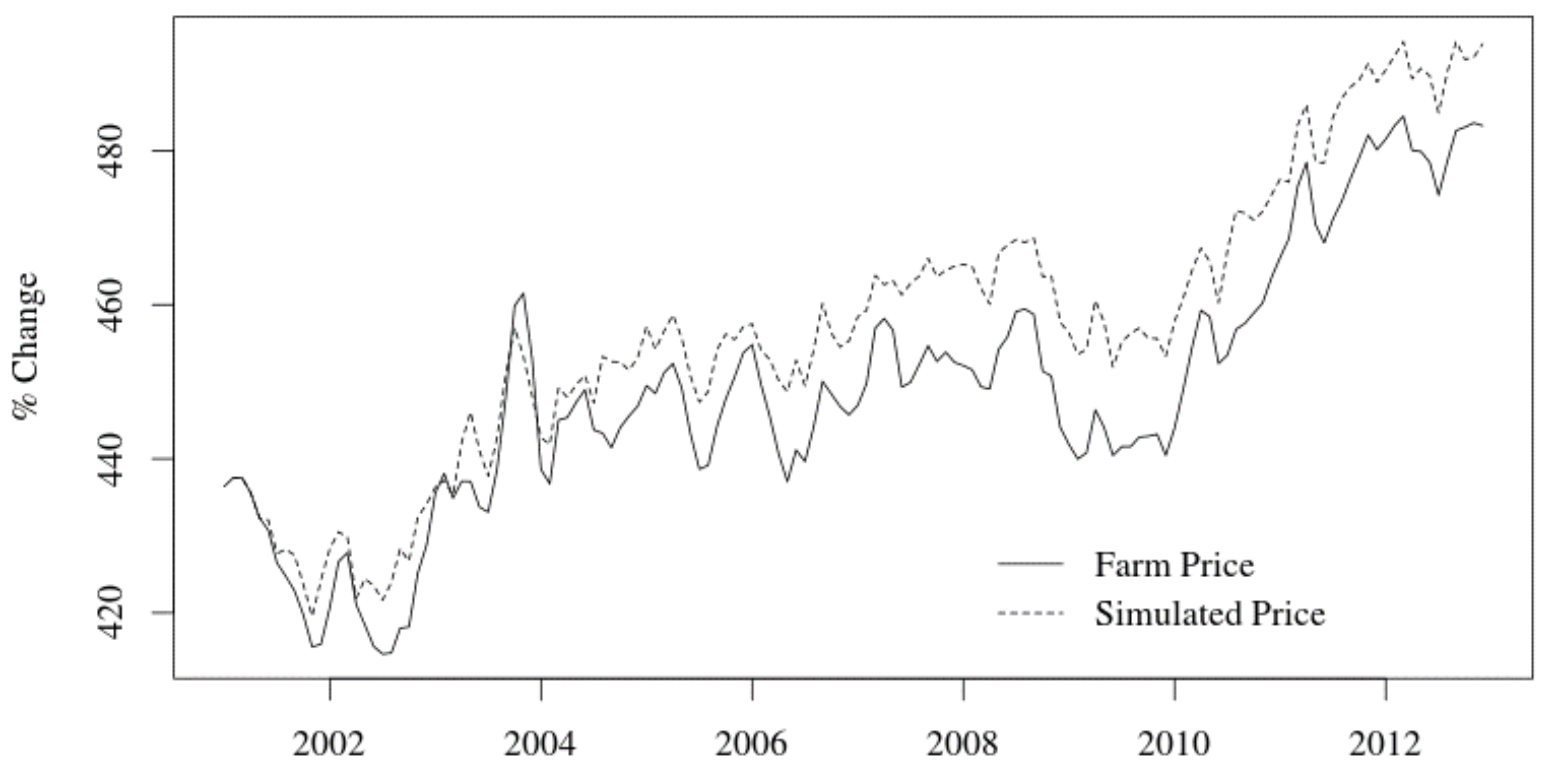

Figure 6. Farm Price Counterfactual Analysis - Symmetric Response to Farm, Retail and Wholesale Price Changes 
Farm Prices Under Symmetry, Scanner Data: Case 3

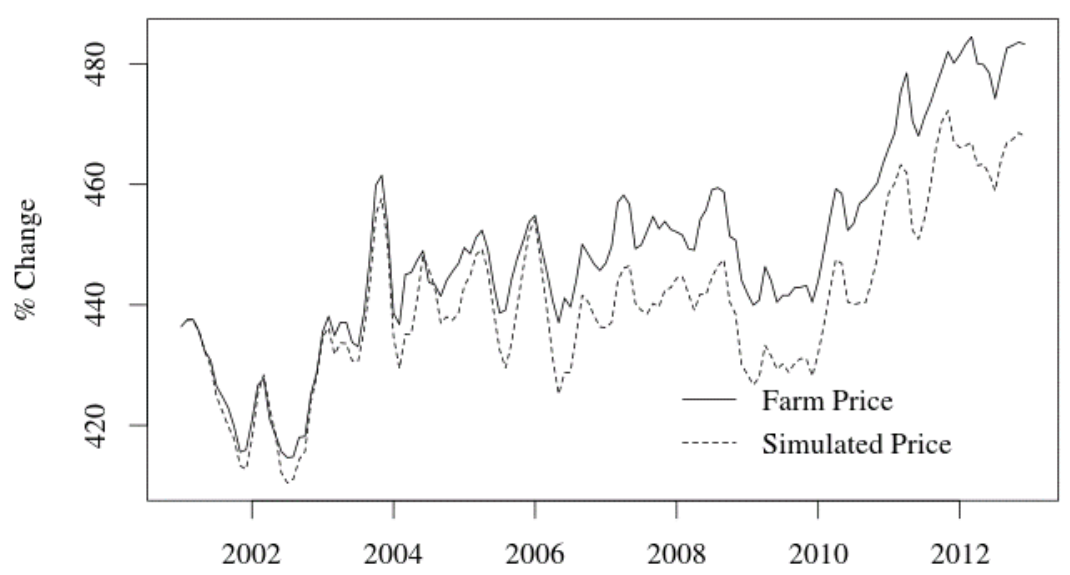

Farm Prices Under Symmetry, Scanner Data: Case 5

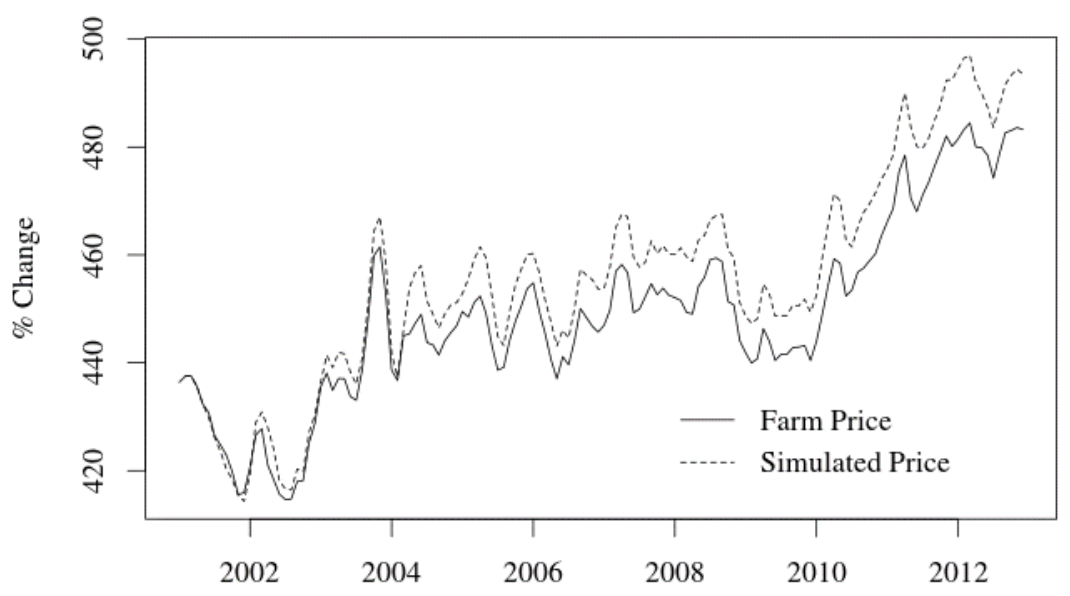

Farm Prices Under Symmetry, Scanner Data: Case 4

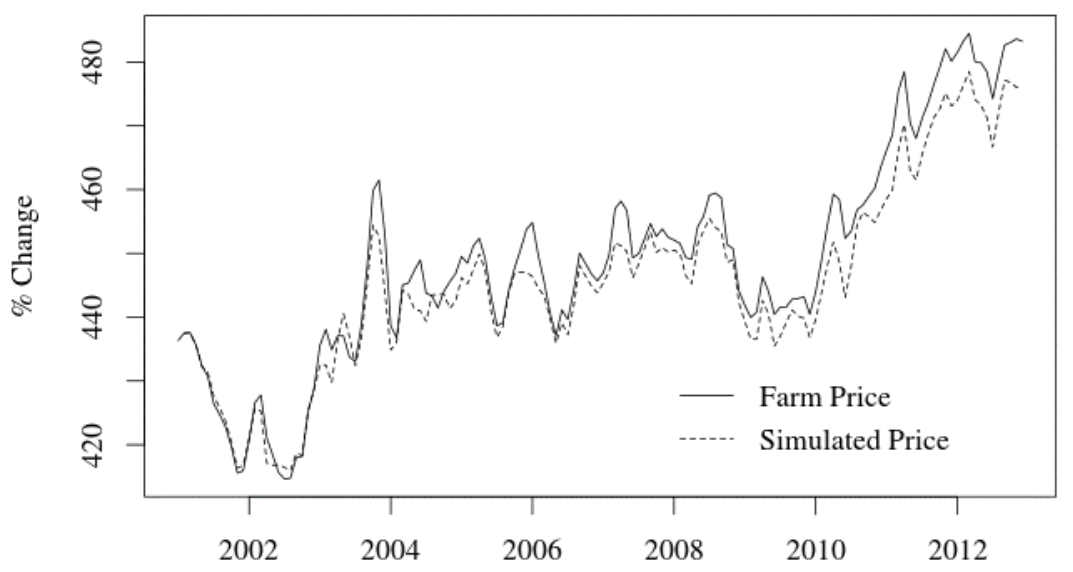

Farm Prices Under Symmetry, Scanner Data: Case 6

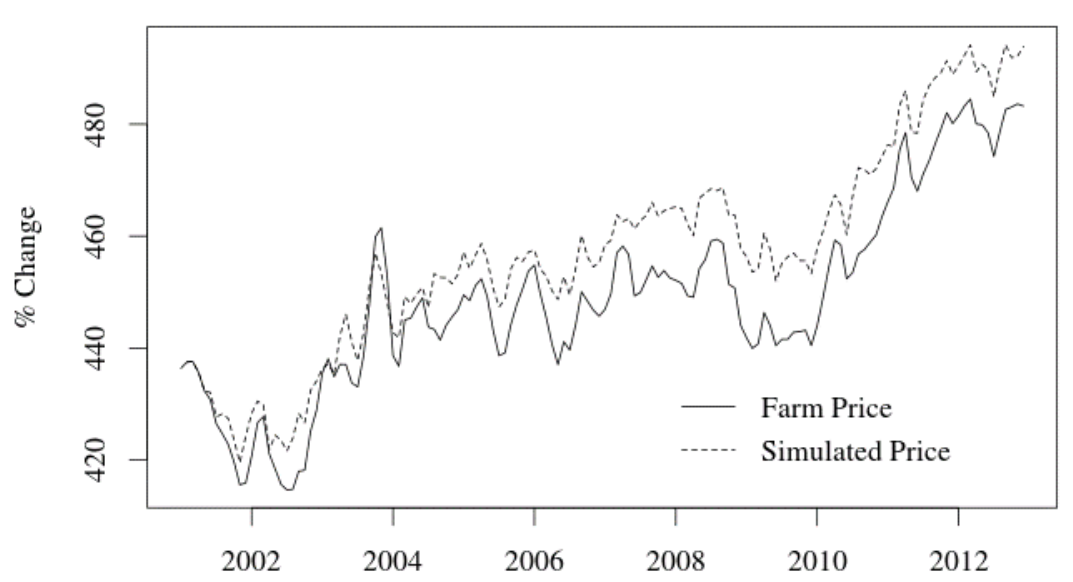

Figure 7. Farm Price Counterfactual Analysis 
Table 1. Results from the Enders-Siklos (2001) Test for Threshold Cointegration (TC)

\begin{tabular}{|c|c|c|c|c|c|}
\hline \multirow[t]{2}{*}{ Relationship } & \multicolumn{5}{|c|}{ Cointegration Test-Statistics } \\
\hline & $t M a x$ & C.V. & $\Phi$ & C.V. & threshold \\
\hline \multicolumn{6}{|l|}{$T C 1$} \\
\hline BLS-Wholesale-Farm & $-3.62 * *$ & -2.14 & $14.57 * *$ & 6.01 & 0 \\
\hline Scanner-Wholesale-Farm ${ }^{a}$ & $-4.11^{* *}$ & -1.98 & $13.33^{* *}$ & 6.28 & 0 \\
\hline Scanner-Wholesale-Farm ${ }^{b}$ & $-3.19^{* *}$ & -1.91 & $9.83^{* *}$ & 6.35 & 0 \\
\hline \multicolumn{6}{|l|}{$T C \mathscr{2}$} \\
\hline BLS-Wholesale-Farm & $-3.89^{* *}$ & -1.90 & $14.96^{* *}$ & 7.08 & 3.85 \\
\hline Scanner-Wholesale-Farm ${ }^{a}$ & $-4.24^{* *}$ & -1.92 & $13.67^{* *}$ & 7.41 & -6.19 \\
\hline Scanner-Wholesale-Farm ${ }^{b}$ & $-3.10^{* *}$ & -1.73 & $10.50^{* *}$ & 7.56 & 4.05 \\
\hline
\end{tabular}

Notes: The null hypothesis under test is no cointegration. Approximate critical values for the tMax and $\Phi$ tests are tabulated by Enders and Siklos (2001). The critical values (C.V.) reported correspond to the 0.05 significance level. ** indicates the rejection of the null hypothesis at the 0.05 significance level. (a) refers to monthly data, and $(b)$ refers to weekly data. 
Table 2. Estimation Results from Structural TVEC Models using Monthly Data (Retail Equation)

\begin{tabular}{|c|c|c|c|c|}
\hline \multirow[b]{2}{*}{ Regressor } & \multicolumn{2}{|c|}{ Monthly BLS } & \multicolumn{2}{|c|}{ Monthly Scanner } \\
\hline & Coefficient & T-Value & Coefficient & T-Value \\
\hline Constant & $0.559^{* *}$ & 2.036 & $2.332^{* * *}$ & 3.256 \\
\hline$E C T_{t-1}^{+}$ & $-0.162 * * *$ & -3.461 & $-0.558^{* * *}$ & -5.590 \\
\hline$E C T_{t-1}^{-}$ & $-0.114^{* * *}$ & -3.008 & $-0.860 * * *$ & -10.261 \\
\hline$\triangle P B_{t-1}^{+}$ & 0.005 & 0.036 & - & - \\
\hline$\triangle P B_{t-1}^{-}$ & $-0.612^{* * *}$ & -3.450 & - & - \\
\hline$\triangle P B_{t-2}^{+}$ & -0.016 & -0.117 & - & - \\
\hline$\triangle P B_{t-2}^{-}$ & -0.072 & -0.380 & - & - \\
\hline$\triangle P B_{t-3}^{+}$ & -0.081 & -0.631 & - & - \\
\hline$\triangle P B_{t-3}^{-}$ & 0.266 & 1.456 & - & - \\
\hline$\triangle P B_{t-4}^{+-3}$ & 0.035 & 0.270 & - & - \\
\hline$\triangle P B_{t-4}^{-}$ & -0.020 & -0.115 & - & - \\
\hline$\triangle P S_{t-1}^{+-4}$ & - & - & $-0.239^{* *}$ & -2.064 \\
\hline$\triangle P S_{t-1}^{-}$ & - & - & $0.202^{*}$ & 1.697 \\
\hline$\triangle P S_{t-2}^{+}$ & - & - & -0.037 & -0.516 \\
\hline$\triangle P S_{t-2}^{-2}$ & - & - & 0.228 & 1.300 \\
\hline$\triangle P S_{t-3}^{+}$ & - & - & $-0.178^{*}$ & -1.920 \\
\hline$\triangle P S_{t-3}^{-}$ & - & - & $0.339^{* * *}$ & 2.626 \\
\hline$\triangle P S_{t-4}^{+-3}$ & - & - & 0.145 & 1.222 \\
\hline$\triangle P S_{t-4}^{-}$ & - & - & $-0.210^{*}$ & -1.700 \\
\hline$\triangle P W_{t}^{+}$ & 0.036 & 0.512 & $0.367 *$ & 1.908 \\
\hline$\triangle P W_{t}^{-}$ & -0.091 & -1.010 & 0.051 & 0.194 \\
\hline$\triangle P W_{t-1}^{+}$ & 0.069 & 0.968 & -0.340 & -1.165 \\
\hline$\triangle P W_{t-1}^{-1}$ & 0.014 & 0.148 & -0.211 & -0.869 \\
\hline$\triangle P W_{t-2}^{+1}$ & 0.048 & 0.656 & 0.071 & 0.297 \\
\hline$\triangle P W_{t-2}^{-}$ & -0.120 & -1.268 & $-0.572^{* *}$ & -2.153 \\
\hline$\triangle P W_{t-3}^{+}$ & 0.060 & 0.841 & $-0.356^{*}$ & -1.672 \\
\hline$\triangle P W_{t-3}^{-}$ & -0.092 & -1.022 & 0.303 & 1.210 \\
\hline$\triangle P W_{t-4}^{+}$ & $-0.139^{* * *}$ & -1.988 & 0.224 & 1.504 \\
\hline$\triangle P W_{t-4}^{-}$ & -0.108 & -1.239 & 0.213 & 1.183 \\
\hline$\triangle P F_{t}^{+}$ & -0.012 & -0.176 & $-0.489^{* * *}$ & -3.014 \\
\hline$\triangle P F_{t}^{-}$ & $0.241^{* * *}$ & 3.016 & -0.110 & -0.538 \\
\hline$\triangle P F_{t-1}^{+}$ & -0.064 & -0.933 & 0.144 & 0.730 \\
\hline$\triangle P F_{t-1}^{-}$ & 0.076 & 0.908 & 0.047 & 0.232 \\
\hline$\triangle P F_{t-2}^{+}$ & $0.117^{*}$ & 1.698 & -0.134 & -0.455 \\
\hline$\triangle P F_{t-2}^{-}$ & $0.141^{*}$ & 1.699 & 0.347 & 1.440 \\
\hline$\triangle P F_{t-3}^{+}$ & -0.049 & -0.730 & 0.270 & 1.568 \\
\hline$\triangle P F_{t-3}^{-}$ & 0.086 & 1.082 & 0.069 & 0.374 \\
\hline$\triangle P F_{t-4}^{+}$ & 0.049 & 0.722 & $-0.380^{* * *}$ & -2.639 \\
\hline$\triangle P F_{t-4}^{-}$ & $0.169^{* *}$ & 2.083 & $-0.331^{* *}$ & -2.156 \\
\hline $\begin{array}{l}\text { Adj. R-squared } \\
\text { Cointegrating Term }\left(E C T_{t-1}\right)\end{array}$ & 0.434 & & 0.436 & \\
\hline Constant & 167.890 & & 241.345 & \\
\hline$\triangle P W_{t-1}$ & 0.970 & & 0.686 & \\
\hline$\triangle P F_{t-1}$ & -0.129 & & 0.009 & \\
\hline
\end{tabular}

Notes: ${ }^{* * *},{ }^{* *}$ and $*$ indicate statistical significance at the $0.01,0.05$ and 0.10 level, respectively. The lag length was determined using the AIC. 
Table 3. Results from the Slope-Based Test of Symmetry in Structural TVEC Models

\begin{tabular}{lcc}
\hline Dependent Variable & Long Run Adjustment & Short Run Adjustment \\
\hline & $H_{0}: b_{i 1}^{+}=b_{i 1}^{-}$ & $H_{0:} \sum_{k=1}^{p} c_{i j, k}^{+}=\sum_{k=1}^{p} c_{i j, k}^{-}$ \\
\cline { 2 - 3 } Monthly BLS & $0.776[0.380]$ & \\
BLS & $0.001[0.992]$ & $0.157[0.693]$ \\
Wholesale & $0.433[0.512]$ & $1.240[0.268]$ \\
Farm & & $0.755[0.387]$ \\
Monthly Scanner & $12.754[0.000]$ & \\
Scanner & $0.979[0.325]$ & $7.918[0.005]$ \\
Wholesale & $0.074[0.787]$ & $0.450[0.504]$ \\
Farm & & $0.006[0.938]$ \\
Weekly Scanner & $0.408[0.523]$ & $2.102[0.148]$ \\
Scanner & $0.111[0.739]$ & $0.198[0.656]$ \\
Wholesale & $0.001[0.983]$ & $0.182[0.669]$ \\
Farm &
\end{tabular}

Notes: $H_{0}$ describes the respective null hypotheses under test. For the short-run adjustment, the null hypothesis corresponds to equation $i=1,2,3$, variable $j=2,3,4$, and all $k=1, \ldots, p$, where $p$ is the number of lags in the estimated structural TVEC model. Corresponding p-values for $F$ tests are given in brackets. 
Table 4. Descriptive Results from the Impulse Response Based Test of Symmetry in Structural TVEC Models

\begin{tabular}{lccc}
\hline TVEC Model & & Asymmetric Price Response & \\
\hline Shock to Farm & Farm & Wholesale & Retail \\
Monthly BLS & none & none & negative \\
Monthly Scanner & none & none & none \\
Weekly Scanner & none & none & none \\
Shock to Wholesale & & & Retail \\
Monthly BLS & Farm & Wholesale & positive \\
Monthly Scanner & positive & positive & none \\
Weekly Scanner & none & none & none \\
& none & none & Retail \\
Shock to Retail & & & positive \\
Monthly BLS & Farm & Wholesale & none \\
Monthly Scanner & none & none & none \\
Weekly Scanner & none & none & \\
\hline
\end{tabular}

